\title{
Lean and green product development: two sides of the same coin?
}

\author{
Glenn Johansson and Erik Sundin
}

\section{Linköping University Post Print}

\section{Tweet}

N.B.: When citing this work, cite the original article.

Original Publication:

Glenn Johansson and Erik Sundin, Lean and green product development: two sides of the same coin? 2014, Journal of Cleaner Production, (85), 104-121.

http://dx.doi.org/10.1016/j.jclepro.2014.04.005

Copyright: Elsevier

http://www.elsevier.com/

Postprint available at: Linköping University Electronic Press

http://urn.kb.se/resolve?urn=urn:nbn:se:liu:diva-113494 
Lean and Green Product Development: Two Sides of the Same Coin?

Glenn Johansson ${ }^{1}$, Erik Sundin ${ }^{2}$

${ }^{1}$ Dept. of Industrial Engineering and Management, School of Engineering, Jönköping university ${ }^{2}$ Dept. of Management and Engineering, Linköping university 


\title{
Lean and Green Product Development: Two Sides of the Same Coin?
}

\begin{abstract}
This paper compares and contrasts the lean product development (LPD) and green product development (GPD) concepts through a systematic literature review including 102 journal publications. The review resulted in 14 findings that were organised according to four dimensions: general, process, people and tools/techniques. A number of similarities between the concepts were found. For example, implementation of both concepts calls for a systems perspective where the dimensions of process-people- tools/techniques are linked holistically. Differences between the LPD and GPD concepts lie in: their goal and focus, value construct, process structure, performance metrics, and tools/techniques used. The findings do not unambiguously support that "green thinking is thinking lean" and consequently it cannot be argued that LPD and GPD are two sides of the same coin, meaning that LPD automatically leads to greener products or that GPD ensures improvements and efficiency in the product development process. However, it is reasonable to conclude that LPD and GPD belong to the same "currency". That is, the concepts share a number of similarities that indicate a synergistic relationship. This synergistic relationship has been accentuated by a nine propositions where the potential for cross-field learning is shown.
\end{abstract}

Keywords: Lean; Green; Sustainable; Product development; Product design; Review

\section{Introduction}

"Green thinking is thinking lean". This was stated by Professor Sobek from Montana State University, USA, in September 2011 during his talk on "Sustainable production: A global challenge" at an international seminar in Gothenburg, Sweden. The talk portrayed potential synergies between the lean and green concepts. The primary message from the talk was that adopting and implementing the lean approach, with its focus on waste reduction, naturally leads to more environmentally sustainable operations. Similar arguments have been put forward by other scholars. Porter and van der Linde (1995), for example, claim that resource inefficiencies, which often occur in companies in the form of incomplete material utilization or poor process controls, cause unnecessary waste, defects, and stored materials. From a lean perspective, such resource inefficiencies should be minimized because they do not contribute to added value. Likewise, reduction or elimination of resource inefficiencies is also sound from a sustainability perspective since inefficiencies lead to increased environmental burdens. Dües et al., (2013, p. 98) state that "lean serves as a catalyst for green, meaning it facilitates a company's transformation towards green". Some empirical studies have further strengthened the notion that there exist synergies between the lean and green concepts (e.g. King and Lenox, 2001).

Nowadays, the lean and green concepts are fairly well established within both academia and industry, even though there are multiple interpretations of their meaning and contents. The origin of the lean concept can be traced back to Japan decades ago, and in particular, Toyota Motor Corporation (Monden, 1983; Ohno, 1988). The "lean" term was first coined by Womack et al. (1991) in their seminal book The Machine that Changed the World. A critical point in the lean approach is 
value creation (Hines et al., 2004), and implementation of the approach in businesses has largely focused on eliminating non-value adding activities. The green concept is one of three pillars of sustainable development, or sustainability, which was introduced in the report Our Common Future presented by the World Commission on Environment and Development, also referred to as the Brundtlandt Commission (WCED, 1987). In business practice as well as in much academic literature, sustainability has largely been interpreted as the concern for environmental issues in order to achieve "green" operations and products. For example, in their review of literature on sustainable supply chain management, Seuring and Müller (2008) found that $73 \%$ of the papers addressed environmental issues. Correspondingly, this paper also refers to the environmental dimension of sustainability.

Despite the increasing attention that has been paid to the lean and green concepts as essential ingredients in successful business operations, relatively few attempts have been made to analyse how the two concepts relate to each other. In a search for peer-reviewed papers that contained the words "lean" and one or more of the words "green", "sustainable", "clean" or "environmental", Biggs (2009) found only seven journal papers that report results where the two concepts are treated in an integrated way. This indicates that the lean and green research fields have developed relatively independent of each other. Another finding from the literature search was that the studies primarily addressed the production operations within a company. Thus, the potential relationships between lean product development (LPD) and green product development (GPD) seem to be largely neglected in literature. Only a few attempts have been made to integrate the LPD and GPD tools/techniques, for example (Chapas et al., 2010); Inoue et al., 2012). Chapas et al. (2010) developed a tool/technique based on Six Sigma factors: Supplier, Input, Process, Output, and Customer (SIPOC). A modified SIPOC tool/technique was developed and refined through discussion with participating companies. The tool/technique provides a way of thinking about sustainability that can be integrated into existing product development management tools/techniques, new product development processes, and stage-gate systems. The tool/technique developed by Inoue et al. (2012) is a preference set-based design tool/technique, which enables a flexible and robust product design under various sources of uncertainty while capturing the designers' preference based on his/her knowledge or experience. This tool/technique works as decision-making support for GPD in the early phase of the development process and considers the various design uncertainties.

It is a bit surprising that the potential relationships between LPD and GPD have received scarce attention among scholars and practitioners, since new product development (NPD) has for many years been considered to be one of the key operations that determine business success (e.g. Clark and Fujimoto, 1989), and recent research has indicated that product development plays a central role in a company's efforts to become both lean and green (Anand and Kodali, 2008; Kleindorfer et al., 2005). Although there exist literature reviews of the LPD and GPD research fields respectively (e.g. Baumann et al., 2002; León and Farris, 2011), no comprehensive review is available where the two fields are compared and contrasted. The current knowledge of potential conflicts, synergies, or overlaps between LPD and GPD is therefore poor.

Based on these premises, the starting point for this paper is the lack of insights regarding the relationships between the concepts of lean and green product development. The purpose of this paper is twofold. First, the intention is to scrutinize publications within the LPD and GPD fields to detect definitions and elements of the concepts, tools/techniques to be used, implementation issues, 
etc. The idea is to illuminate differences and similarities in order to allow the fields to be compared and contrasted. Second, based on the comparison between the two research fields, future promising research avenues will be suggested.

The paper is organized as follows. Following this introduction, the research approach and a descriptive analysis of the identified papers are outlined. Next, the LPD and GPD concepts are briefly introduced followed by an analysis where research on LPD and GPD is compared and contrasted. Based on the comparison, a number of propositions that reflect potential cross-field learning between the LPD and GPD fields are suggested. The paper ends with a discussion and conclusions.

\section{Research approach and descriptive analysis}

This section describes how the literature review presented in this paper was carried out. Additionally, a descriptive analysis is presented where statistics from the literature search are outlined.

\subsection{Research approach}

This study rests upon a systematic literature review, which is "a review with a clearly stated purpose, a question, a defined search approach, stating inclusion and exclusion criteria, producing a qualitative appraisal of articles" (Jesson et al., 2012, p.165). The systematic approach contributes to its method being both explicit and reproducible (Booth et al., 2012). The method used in this paper follows the systematic review procedure suggested by Jesson et al. (2012):

1) Mapping the field through a scoping review: The review plan is prepared, including specification of the method and protocol to be used for the review. This involves the definition of the research purpose and scope as well as specification of key words, databases and criteria for inclusion and exclusion of publications.

2) Comprehensive search: Papers are searched and collected from the specified databases using the key words and the inclusion/exclusion criteria. The outcome from the search is documented.

3) Quality assessment: The full papers are read and it is decided whether or not papers should be included in the review. Reasons for exclusion are documented.

4) Data extraction: The relevant data from the included papers are extracted and organized.

5) Synthesis: The data from the individual papers are synthesized into a story and tables that summarize and analyse the papers.

6) Write-up: A balanced, impartial and comprehensive document (a report or a paper) is written where the method and findings are presented so that the review can be replicated.

The purpose and research scope were defined on the basis of the identified lack of cross-fertilization between the LPD and GPD fields. The fields have developed independently with limited interaction between the two. As the purpose of this paper was to compare and contrast the two fields of LPD and GPD, each field was searched separately. The following databases were used to identify relevant publications: ABI Inform (ProQuest), Scopus, Business Source Premier, Science Direct, and Emerald. A number of keyword combinations were defined to both replicate and complement other reviews in the two fields (e.g. Baines et al., 2006; Baumann et al., 2002; Ilgin and Gupta, 2010; León and Farris, 2011). The keyword combinations are specified in Table 1. The search was limited to papers where these keywords appeared in the paper title, abstract, or subject terms. 
Table 1: Keyword combinations for the literature search.

\begin{tabular}{l|l}
\hline Lean & \\
Toyota & \\
Kaizen & and Product development or Product design \\
Six sigma & \\
\hline Green & \\
Sustainable & \\
DFE & \\
Ecodesign & \\
\hline
\end{tabular}

Literature was searched from January 2000 up until December 2012. This time period was selected because up-to-date literature was considered most relevant for comparison of the two fields.

Baumann et al. (2002) covered publications through 1999 in their review of GPD, whereas León and Farris' (2011) LPD review indicated that the majority of the publications have been produced after 2001. Including these two publications as well as other recent review publications in each field ensured that publications prior to 2000 were also covered, thus adding to the completeness of the literature covered in this paper. Only papers published in peer-review English journals were included, owing to the fact that such papers have undergone a quality check through a blind review process. Conference papers and books were excluded, which definitely induces a risk that some relevant publications have been overlooked. Still, papers in peer-reviewed journals are likely to represent the two fields fairly well and provide a sound basis for capturing the quintessence of each field. Moreover, some of the review papers identified in each field also covered publications other than peer-reviewed journal papers. It can hence be argued that the foundation for the comparison between the LPD and GPD fields is rigorous. It should be noticed, however, that the idea behind this paper was not to carry out an all-inclusive review of each field, but to provide insight into differences and similarities between the fields.

A total of 830 hits were produced in the search for LPD papers. Out of these, 49 were deemed potentially relevant based on the text outlined in the papers' abstracts. The gross result for GPD papers was 3125 , and based on the abstracts 85 papers were initially selected. All selected papers were read briefly, and this produced a list of 33 LPD papers and 65 GPD papers that were considered interesting to include in the review. Using a snowball sampling technique, where the reference lists of the selected papers were studied to find papers that might have been missed in the database searches, two additional LPD papers and two GPD papers were identified. The final list of publications thus accounted for 102 papers, distributed as 35 LPD and 67 GPD papers. As the review focused on comparison of current knowledge within the LPD and GPD fields, papers that had a managerial perspective on the LPD and GPD concepts were considered to be of most interest. Such papers have been assumed to be of more value for potential cross-field learning than papers that displayed detailed technical contents. Thus, papers that mainly focused on technical details (e.g. optimization of certain product components to ensure reliability) were excluded.

The selected papers were analysed through the content analysis approach (Bryman and Bell, 2011). This involved the use of coding procedures where texts were checked for certain patterns and then used to generate condensed insights on the content (Hoppmann et al., 2011). A predefined coding scheme was specified for extraction and organization of essential data in the papers. The coding 
scheme was inspired by the one Nambisan and Wilemon (2000) used in their literature review. They compared and contrasted NPD literature and software (SW) development literature to identify the potential for knowledge sharing between the two fields. Their coding scheme specified three dimensions: "people", "process", and "tools/techniques". These three dimensions have also been used by Liker and Morgan (2006) to structure principles of LPD, which support the relevance of the dimensions as a basis for the comparison. To be able to cover constructs that did not fit the peopleprocess-tools/techniques dimensions, an additional "general" dimension was defined. For each of the four dimensions a set of sub-categories were specified to make the insights into the LPD and GPD more detailed.

All selected papers were read in detail and prominent constructs were organised into the four dimensions and their sub-categories. A coding manual that contained more specific instructions for the classification was used as support for the organisation of the constructs (Bryman and Bell, 2011). It should be noted that although the sub-categories were defined prior to reading the literature, they were slightly revised during the early analysis to better fit the emerging findings (c.f. Seuring and Müller, 2008). Because a comparison between the fields of LPD and GPD was the focus, it was not possible to use predefined codes for all sub-categories. In some cases, an open coding procedure was used where an overall judgement of the literature related to some sub-categories was performed (Strauss and Corbin, 1990). The data extracted from the selected papers was synthesized and organized into tables to provide insights into the LPD and GPD concepts, as well as to make the comparison between the concepts explicit.

\subsection{Descriptive analysis}

The allocation of the papers included in the review is illustrated in Figure 1. Evidently, the number of GPD publications accounted for more than double as many publications as the LPD publications, which indicates that scholars have devoted more interest to the GPD field than the LPD field. As can been seen from the figure, there seems to be a trend towards an increasing number of publications during the last few years in both fields (except for the drop of the LPD publications in 2009 and GPD publications in 2012). This could be interpreted as scholars having a growing interest in both fields.

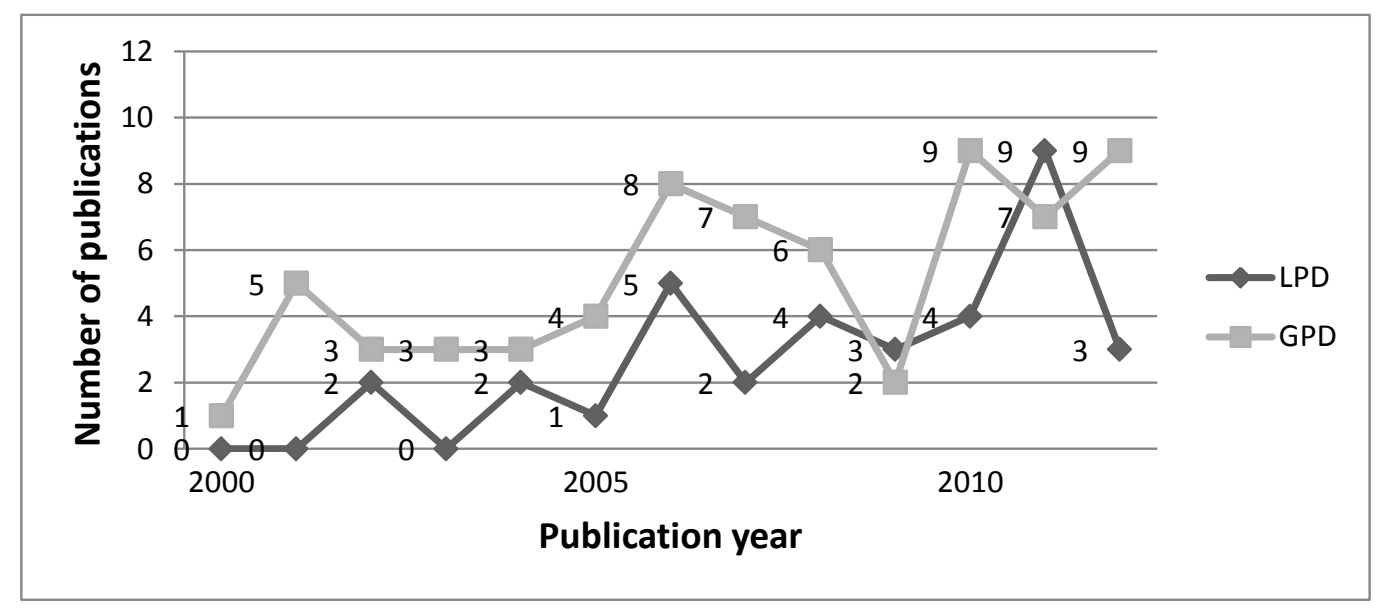

Figure 1: Distribution of publications per year across the period studied.

Inspired by the reviews carried out by Seuring and Müller (2008) and Giannopoulou et al. (2010), research methods used in the reviewed papers were organised into the following categories: 1 ) 
theoretical and conceptual papers; 2) case studies; 3) surveys; 4) literature reviews; and 5) others. These categories have been adopted for classification of LPD and GPD publications. Figure 2 presents the distribution of methods used in the papers within the LPD and GPD fields.
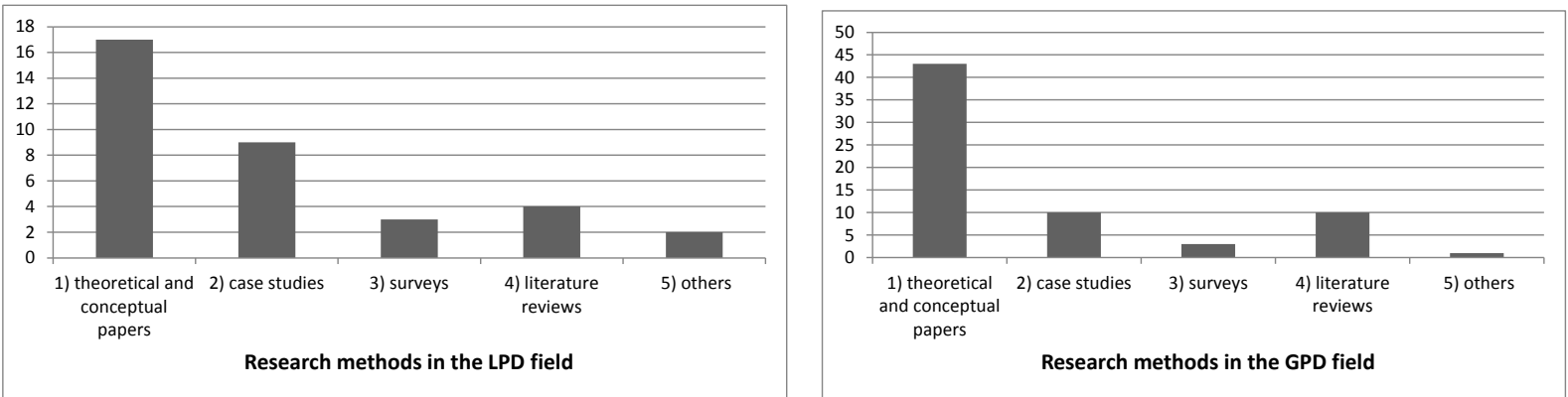

Figure 2: Distribution of research methods used in the LPD and GPD fields.

Notably, the distribution of research methods used in each field is rather similar, even though the total number of papers in the GPD field exceeds the number in the LPD field. Figure 2 shows a clear bias towards theoretical and conceptual papers in both fields. Evidently, the empirical base for LPD is rather weak and much research has presented various conceptual frameworks. Empirical studies where these frameworks have been implemented and experiences from their use are still scarce. Similarly to the LPD field, the GPD field lacks a solid empirical base. The GPD field is biased towards conceptual development of tools/techniques that are assumed to contribute to implementation and success of GPD (c.f. Baumann et al., 2002). The lack of empirical studies might be interpreted as both fields are still in their early phases, even though research has been carried out for a couple of decades.

\section{Introduction to the LPD and GPD concepts}

In this section the LPD and GPD concepts are briefly introduced, including presentations of the origins and definitions of the concepts.

\subsection{The LPD concept}

The lean product development (LPD) concept has its roots in the early 1990s and is often assigned to the seminal work by Womack et al. (1991) and Womack and Jones (1996). Even though their main focus was set on the production operation, these scholars (as well as others) also tried to find explanations for the differences between Japanese and Western automobile manufacturers regarding product development performance (Hoppmann, et al. 2011). Special attention has been devoted to Toyota's product development approach, which can be labelled lean development (Ballé and Ballé, 2005). LPD is also known in the literature as lean new product development (LNPD) (Anand and Kodali, 2008), lean product introduction (LPI) (Haque and James-Moore, 2002; 2004), lean product lifecycle management (Hines et al. 2006), lean design engineering (Baines et al., 2006), Toyota product development (Liker and Morgan, 2006), and Japanese product development (Jacobs and Herbig, 1998). However, there does not seem to be a generally accepted definition of LPD (Hoppmann et al., 2011); only a few examples of explicit definitions were found in the reviewed papers as shown in Table 2. Commonly, scholars refer to the elements of LPD rather than provide precise definitions. 
Table 2: Examples of terminology and definitions of LPD.

\begin{tabular}{|c|c|c|}
\hline Terminology & Definition & Author(s) \\
\hline $\begin{array}{l}\text { Lean product } \\
\text { introduction (LPI) }\end{array}$ & $\begin{array}{l}\text { "[...] application of Lean Thinking to NPI; in particular, } \\
\text { the five lean principles [...] 'specify value', 'identify the } \\
\text { value stream and eliminate waste', 'make the value } \\
\text { flow', 'let the customer pull the process', and 'pursue } \\
\text { perfection'" }\end{array}$ & $\begin{array}{l}\text { Haque and James-Moore (2004, } \\
\text { p.1) }\end{array}$ \\
\hline $\begin{array}{l}\text { Lean new product } \\
\text { development (LNPD) }\end{array}$ & $\begin{array}{l}\text { "The application of lean principles to the NPD process } \\
\text { to eliminate wastes" }\end{array}$ & Anand and Kodali $(2008$, p. 196) \\
\hline $\begin{array}{l}\text { Lean product } \\
\text { development }\end{array}$ & $\begin{array}{l}\text { "Lean product development is defined to meet } \\
\text { customer functional requirements, as far as possible to } \\
\text { reduce wastes and costs, to improve product } \\
\text { performance, so that the product design throughout } \\
\text { the life-cycle has both high technical contributions and } \\
\text { economic profits" }\end{array}$ & Ni et al., (2011, p. 2440-2441) \\
\hline $\begin{array}{l}\text { Lean product } \\
\text { development (LPD) }\end{array}$ & $\begin{array}{l}\text { "LPD is viewed as the cross-functional design practices } \\
\text { (techniques and tools) that are governed by the } \\
\text { philosophical underpinnings of lean thinking - value, } \\
\text { value stream, flow, pull, and perfection - and can be } \\
\text { used (but are not limited) to maximize value and } \\
\text { eliminate waste in product development" }\end{array}$ & Léon and Farris (2011, p. 29) \\
\hline
\end{tabular}

The application of the lean concept to product development is still in its infancy, despite the success of lean initiatives within manufacturing (Schulze and Störmer, 2012). Consequently, no agreement has been reached for how LPD should be defined and conceptualized, but some central elements of LPD have been outlined in the literature. The elements have been assembled into a number of LPD frameworks by various scholars (Haque and James-Moore, 2002, 2004; Hines et al., 2006; Anand and Kodali, 2008; Cooper and Edgett, 2008; Hoppmann et al., 2011; Wang et al., 2011; León and Farris, 2012). Examples of elements in the frameworks include: customer focus, chief engineer, supplier involvement, cross-disciplinary teams, front-loading and overlapping/parallel activities, standardisation of processes, and use of various tools/techniques. By viewing these elements as part of a system it is assumed that the frameworks describe how NPD should be carried out in order to ensure efficient and effective NPD processes. However, these "descriptive frameworks for Lean PD, despite showing apparent overlaps, differ considerably regarding the focus and the number of components they comprise" (Hoppmann et al., 2011 p. 5). A common statement in the LPD literature is that the different LPD elements must not be viewed as isolated elements. Rather, LPD should be addressed from a system perspective, where all elements are aligned into a holistic concept (Liker and Morgan, 2006; Welo, 2011). Clearly, the LPD elements interact with and depend on each other in various ways (Hoppman et al., 2011).

\subsection{The GPD concept}

It was during the early 1990s that green product development (GPD) research gained sufficient volume to be identified as a distinct research area (Boks and McAloone, 2009). In many cases, the research findings were transformed into various tools/techniques aimed at supporting the consideration of environmental issues in NPD (e.g. Brezet and van Hemel, 1997; Simon et al., 1998). According to Boks and McAloone (2009), GPD research has developed since the early days through four transitions: 1) from opportunistic to realistic research; 2) from a product to a systems perspective; 3 ) from an environmental to a sustainability context; and 4) from concept development 
to technology transfer and commercialisation. In the literature, a set of different terms has been used to denote the efforts of making products more environmentally benign. Examples include green product development (GPD) (Chen, 2001), ecodesign (Johansson, 2002), environmentally conscious design (Sakao, 2009), design for environment (DFE) (Fiksel, 1993), sustainable life-cycle design (Ramani et al., 2010), and sustainable product development (Kaebernick et al., 2003). Table 3 shows some terms and definitions found in the literature.

Table 3: Examples of terminology and definitions of GPD.

\begin{tabular}{|c|c|c|}
\hline Terminology & Definition & Author(s) \\
\hline $\begin{array}{l}\text { Green product } \\
\text { development (GPD) }\end{array}$ & $\begin{array}{l}\text { "addresses the environmental issues through product } \\
\text { design and innovation" (p. 196) }\end{array}$ & Chen (2001) \\
\hline Ecodesign & $\begin{array}{l}\text { "ecodesign refers to actions taken in product development } \\
\text { aimed at minimising a product's environmental impact } \\
\text { during its whole life cycle, without compromising other } \\
\text { essential product criteria such as performance and cost" } \\
\text { (p.98) }\end{array}$ & Johansson (2002) \\
\hline $\begin{array}{l}\text { Environmentally } \\
\text { conscious design }\end{array}$ & $\begin{array}{l}\text { "design activity reducing the environmental impacts } \\
\text { throughout the life cycle of a product with conforming the } \\
\text { market" (p. 183) }\end{array}$ & Sakao (2009) \\
\hline $\begin{array}{l}\text { Design for } \\
\text { environment (DFE) }\end{array}$ & $\begin{array}{l}\text { "Design for Environment (DFE) is widely understood among } \\
\text { scholars and industrial practitioners to be the integration } \\
\text { of environmental considerations into product and process } \\
\text { design(p. 4021) }\end{array}$ & Boks and Stevels (2007) \\
\hline
\end{tabular}

Similar to the LPD field, there does not seem to be any commonly agreed upon terminology for the greening of products, and the GPD concept is still not well defined (Chen, 2001). The GDP concept has been claimed to be relevant for different industry sectors, depending on how much drive there is from customers and legislation regarding materials usage and end-of-life treatment (Albino et al., 2012). The GPD literature also contributes a number of elements that are important for developing more environmentally sound products. Notably, scholars have produced numerous tools/techniques that are aimed at supporting product development teams to consider environmental issues (for an overviews Bovea and Perez-Belis, 2012). Others have underscored the importance of the development process, organisation, management system, competences, and motivation (Boks, 2006; Johansson, 2002; Ammenberg and Sundin, 2005; Johansson and Magnusson, 2006). However, the impact in industry is still quite limited (Short et al., 2012).

\section{Comparison between the LPD and GPD concepts}

This section presents the findings from the literature review. Table 4 summarises the comparison between the LPD and GPD concepts. The key findings from the literature review are listed for each of the four dimensions (general-process-people-tools/techniques), including their sub-categories. In total, findings related to 14 sub-categories are presented in the table. In what follows, the findings for each sub-category are described in greater detail. 
Table 4: Summary of the comparison between the LPD and GPD concepts.

LPD

GPD

\section{General}

Drivers/motives

Goal

The value construct

The waste construct

Industrial application

Implementation issues

\section{Process}

\section{Process structure}

Activities
The strive for competitive advantage, through a more efficient and effective product development process, is a key driver for LPD.

The overall goal is to create value for customers by eliminating waste and unnecessary actions in the product development process.

Value is considered to be created when useful information is generated during product development, which ultimately leads to a product that is attractive for customers.

Waste is strongly associated with the product development process per se and refers to activities that are non-value adding.

Examples of applications mainly originate from the automotive and aerospace industry segments, but it has been argued that LPD presumably can be applied in other sectors as well.

Implementation of LPD should be viewed as a long-term step-by-step change process, involving organisation-wide changes in people, processes, and use of tools/techniques and techniques.

Standardisation of routines, activities, tools/techniques, etc. is expected to lead to structured and stable development processes that help to produce predicable results.

The process flow is considered important to minimize waste, while the pull principle, front-loading of activities, setbased engineering and parallel activities are means to achieve a smooth flow.
Competitive advantage is a main goal of GPD, but compliance with regulation and legislation is seemingly a very important driver

The key goal is to ensure the development of products that have minimum negative impact on the natural environment.

Value creation commonly refers to fulfilment of requirements that leads to environmentally benign products.

Waste is primarily considered to be of a physical nature and product-related. The overarching idea is to minimise the amount of waste going to recycling, incineration and landfill.

GPD is considered to be relevant for all industry segments, but especially those industries that have strict legislation for material usage and/or high recovery rates

Implementation of GPD rests upon a holistic perspective where various areas of concern should be considered and GPD can, for example, be integrated with companies' environmental management systems.

GPD is suggested to be integrated into the existing process without any major changes to the process.

Activities relate to all product development phases, but it has been emphasised that major efforts should take place in the early phases. 


\begin{tabular}{|c|c|c|}
\hline Performance metrics & $\begin{array}{l}\text { Performance is measured as both } \\
\text { efficiency and effectiveness of the } \\
\text { product development effort. Many } \\
\text { metrics resemble those found in } \\
\text { traditional "best practice" literature on } \\
\text { NPD. }\end{array}$ & $\begin{array}{l}\text { Several metrics are used to measure } \\
\text { environmental performance; a common metric } \\
\text { is the greenhouse gas metric or the } \mathrm{CO} 2 \\
\text { equivalent metric. Attempts have been made } \\
\text { to combine environmental impact metrics with } \\
\text { economic metrics. }\end{array}$ \\
\hline \multicolumn{3}{|l|}{ People } \\
\hline Competencies & $\begin{array}{l}\text { LPD emphasises the need for technical } \\
\text { excellence in different engineering } \\
\text { disciplines and the key role of the chief } \\
\text { engineer who leads the development } \\
\text { project. }\end{array}$ & $\begin{array}{l}\text { GPD emphasises the roles of product design } \\
\text { engineers, environmental specialists, } \\
\text { environmental champions and project } \\
\text { managers to ensure consideration of } \\
\text { environmental issues in a product } \\
\text { development project. }\end{array}$ \\
\hline Organisation & $\begin{array}{l}\text { The functional organisation plays a } \\
\text { central role in LPD, where co-ordination } \\
\text { is achieved by devising a matrix } \\
\text { organisation in the development projects. }\end{array}$ & $\begin{array}{l}\text { GPD is preferably carried out in cross- } \\
\text { disciplinary product development teams. }\end{array}$ \\
\hline Learning and training & $\begin{array}{l}\text { Learning and training is important to } \\
\text { achieve continuous improvement in the } \\
\text { product development process. }\end{array}$ & $\begin{array}{l}\text { Learning and training must be provided all } \\
\text { product development personnel to ensure that } \\
\text { environmental issues are considered in the } \\
\text { product development process. }\end{array}$ \\
\hline \multicolumn{3}{|l|}{ Tools/techniques } \\
\hline Number of tools/techniques & $\begin{array}{l}\text { The literature offers several different } \\
\text { tools/techniques to be used as part of the } \\
\text { LPD concept, but no commonly agreed } \\
\text { upon list of tools/techniques exists. }\end{array}$ & $\begin{array}{l}\text { An excessive number of tools/techniques have } \\
\text { been developed for GPD, although few have } \\
\text { made a significant breakthrough in industry. }\end{array}$ \\
\hline Types of tools/techniques & $\begin{array}{l}\text { LPD is supported by the use of various } \\
\text { tools/techniques. Some have a product- } \\
\text { oriented focus where quality is at the } \\
\text { core, whereas others address efficiency } \\
\text { and improvement of the product } \\
\text { development process per se. }\end{array}$ & $\begin{array}{l}\text { Many different types of GPD tools/techniques } \\
\text { have been developed with different focus on, } \\
\text { e.g., reducing environmental impacts and } \\
\text { facilitating end-of-life processes. }\end{array}$ \\
\hline
\end{tabular}

\subsection{General}

This section outlines a comparison between the LPD and GPD concepts regarding some general issues. First, drivers/motives are outlined. Second, goals of the concepts are compared. Third, the value construct is discussed. Fourth, the waste construct is presented. Fifth, the industrial application of the two concepts is described. Finally, implementation issues related to each concept are discussed.

\subsubsection{Drivers/motives}

Basically, LPD is driven by harsh competition in the market place. Decades of intensified competition has forced companies to constantly introduce new products on the market. Rapid product 
development has thus become fundamental for competitiveness (e.g. Brown and Eisenhardt, 1995). It has been argued that LPD has the potential to reduce development cycle times and time-to-market (Letens et al., 2011). Actually, one of the central goals of LPD is to speed up the development process through a leaner way of working (Gremyr and Fouquet, 2012). Literature has also stated that LPD supports the strive for reduced development and product costs, high product quality, revenues, and market share (Hoppman et al., 2011). In essence, the main motive for companies to engage in LPD efforts is to ensure efficient and effective product development processes that ultimately result in products that are attractive for customers. A product development process that allows short development cycle times, and where focus is set on provision of value for customers through the delivery of high-quality products, has been assumed to add to competitiveness of companies.

GPD is also driven by the competitive situation on the market. Products with improved environmental performance are assumed to add to the competiveness of companies (Lenox et al., 2000; Vercalsteren, 2001; McDonough and Braugart, 2002). According to Albino et al. (2012), GPD can lead to a significant source of competitive advantage when it allows for either product differentiation or low cost manufacturing. In a literature study by Segarra-Ona et al. (2011), the following benefits of GPD were found: competitiveness improvements, cost reduction, better company image and improved NPD performance. In addition, Lee and Kim (2011) found GPD drivers for strategic reasons, to increase competitiveness and to follow legislation. Short et al. (2012) found, based on a study of the practice of GPD in Swedish and UK companies, that the strongest drivers for GPD are the demand from the market/customers and regulations. Consequently, an additional important driver for companies to implement GPD is compliance with regulation and legislative requirements (Chen, 2001; Santos-Reyes and Lawlor-Wright, 2001; Kleindorfer et al., 2005; Boks and McAloone, 2009; Sakao, 2009; Huang et al., 2010). Legislation has during recent years become more rigorous in many regions of the globe (Yang and Chen, 2011). For example, within the European Union a number of different directives (WEEE - Waste Electrical and Electronic Equipment Directive, RoHS - Restriction of Hazardous Substances Directive, EuP - Energy Using Products directive, ELV End of life vehicles directive) have been launched that aim at improving the environmental performance of products (Johansson, 2006; Santini et al., 2010). However, the uncertainty inherent in the evolution of environmental trends, regulation and legislative requirements makes the GPD efforts difficult (Kleindorfer et al., 2005). Despite potential advantages, the commercial benefits of GPD have been found to be somewhat ambiguous. Short et al. (2012) maintain that at its best GPD can provide a positive impact on the economic performance of the company. At its worst, it adds nothing to the company's economic performance but might in that case still be used for marketing.

Finding 1: The strive for competitive advantage, through a more efficient and effective product development process, is a key driver for LPD. Competitive advantage is also a main goal of GPD, but compliance with regulation and legislation is seemingly a very important driver.

\subsubsection{Goals}

Toyota, the company most strongly associated with the lean concept, has received special attention during the last decades due to its remarkable commercial performance. The company has practiced its lean activities based on the underlying philosophy of "the Toyota Way" both in the production operations and NPD activities. "The foundation of the Toyota Way is a long-term philosophy of adding value to customers and society" (Liker and Morgan, 2011 p. 18). Following this fundamental philosophy, much LPD literature emphasises the ultimate goal of providing customer value (e.g. 
Haque and James-Moore, 2004, 2006; Baines et al., 2006; Hines et al., 2006; Anand and Kodali, 2008; Hoppmann et al., 2011; Wang et al., 2011; León and Farris, 2011). The focus on value creation also means that non-value adding activities should be reduced or eliminated (Nepal et al., 2011). Such non-value adding activities, or waste, are activities that do not add any value to the product and must be avoided during the product development process. Representing a large proportion of the LPD literature, Haque and James-Moore (2004) argue that the overall goal of LPD is to eliminate waste and unnecessary actions, and link all product development phases in a continuous sequence to create value for customers.

GPD has the goal to improve companies' performance and aims to reduce the overall costs and environmental impacts of waste production and disposal by optimising energy and material consumption, minimising waste generation, or by reusing process output waste streams as new raw materials for other processes (DeMendonca and Baxter, 2001; Chung and Tsai, 2007). The different definitions outlined earlier clearly indicate that the core of GPD is to reduce the negative environmental impacts. According to Choi et al. (2008), GPD is based on life-cycle thinking and involves development procedures that minimise material and energy consumption while maximising the possibility for reuse and recycling. Adding to this topic, Chung and Tsai (2007) have investigated the relationship between GPD activities and new product activities, and between GPD activities and new product performance, by means of a questionnaire completed by 107 managers from 86 hightech companies in Taiwan. In that study it was revealed that the companies with better implementation of development strategies of new products have better development performance of new products, while the companies with a higher degree of implementation of green design activities and better implementation of development strategies of new products have better development performance of new products (Chung and Tsai, 2007).

Finding 2: The overall goal of LPD is to create value for customers by eliminating waste and unnecessary actions in the product development process. The key goal of GPD is to ensure the development of products that have minimal negative impacts on the natural environment.

\subsubsection{The value construct}

In LPD, value must be specified from both the ultimate customer, i.e. the end customer buying the product, and the internal and external stakeholders (Haque and James-Moore, 2002; 2004; Hines et al., 2006). Internal stakeholders are those functions, groups or individuals that carry out downstream activities in the product development process and rely on information produced in preceding activities. External stakeholders, apart from the end customers, refer primarily to suppliers that are involved in the NPD process. They produce and exchange information that is essential for the progress of the NPD process. However, despite the creation of value being stressed in the literature as a central goal of LPD, a precise definition of what constitutes value in a product development context is still absent (Baines et al., 2006). Which activities add value in product development is unclear, even though there is a consensus that value is added in product development when useful information is generated, and therefore the key areas of value creation in the NPD process remain unresolved (Schulze and Störmer, 2012). Still, León and Farris (2011 p. 39) maintain "value in PD processes appears to be found in the information itself, which is transferred in the form of interim deliverables". Anand and Kodali (2008) add that value within the NPD processes is not just developed as a function of the Fit, Form, Function and Timeliness (FFFT) of the information; it is also related to how well the actions during the NPD process ensure that the product meets the FFFT desires of the 
customers. Although there seems to be a consensus among scholars today regarding the strong connection between LDP and value creation, it is a shift from the early focus on waste minimization, quality, cost, and delivery as major goals of LPD (Baines et al., 2006).

Within the GPD field, the importance of value creation is also acknowledged. However, when value is raised as a construct it most often refers to fulfilment of needs of specific customers that search for safe and environmentally benign products, which induces an opportunity for companies to provide additional value (Hong et al., 2009). GPD performance has been found to create a positive effect on financial performance at high-tech companies in Taiwan (Huang and $\mathrm{Wu}, 2010)$. However, Chen (2001) has found that GPD and stricter environmental standards might not necessarily benefit the environment. An underlying assumption in most GPD research is that development of greener products leads to competitive advantages. Consequently, scholars have maintained that a strong customer focus needs to be adopted in order to achieve successful green product development (Johansson, 2002). Still, research has reported that it is hard to provide evidence that there is a direct link between GPD and increased customer value. Actually, studies have shown that companies have doubts whether GPD results in competitive advantage in terms of sales and market share (Boks and McAloone, 2009). Although value creation through GPD remains as a topic for debate, another related aspect maintained in the literature is that GPD provides risk reduction. One reason for companies to carry out GPD is not only to create value, but also to reduce risks associated with poor legal compliance (Kleindorfer et al., 2005). Thus, development of environmentally sound products reduces the risk of being held accountable for damages to the natural environment. According to Berchini and Bowedes (2005), GPD represents a strategic option for manufacturers for value creation, meaning that good environmental product performance adds value to the product.

Finding 3: In LPD, value is considered to be created when useful information is generated during product development, which ultimately leads to a product that is attractive for customers. In GPD, value creation commonly refers to fulfilment of requirements that leads to environmentally benign products.

\subsubsection{The waste construct}

Elimination of waste has traditionally been at the heart of the lean approach, and thus waste is also a central construct in the LPD literature (Baines et al., 2006; Gautam et al., 2007). It is generated by activities that do not add value from a customer perspective and for which they are unwilling to pay. Any activity that does not add customer value or strategic value to the company in the form of new knowledge is to be considered as waste (Welo, 2011). Each and every wasteful activity should be avoided. However, what constitutes waste is much less straightforward in a product development context compared to manufacturing (Letens et al., 2011). Several activities during product development are intended to reduce risk, such as iterative testing and redesign to improve the product. These activities do not directly add customer value and resemble the non-value adding inspection and rework activities in a manufacturing context. However, the activities are important to perform to ensure that the product will ultimately meet customer needs and should therefore not be targeted for reduction or elimination (Shulze and Sörmer, 2012). The LPD literature outlines various wastes potentially inherent in the product development process (Yang and Cai, 2009). A number of different types of waste have been discussed in the literature; Table 5 presents two examples of waste sets. A more extensive overview of various types of wastes extant in the LPD literature can be 
found in Wang et al. (2011). Although, as argued by León and Farris (2011), there exists no single agreed-upon list of wastes, there seems to be an overlap between the waste sets presented by various authors.

Table 5: Examples of waste in the product development process (condensed descriptions).

\begin{tabular}{ll}
\hline Anand and Kodali (2008) & Nepal et al. (2011) \\
\hline $\begin{array}{l}\text { Over-production or early production (too many products in } \\
\text { parallel; specifications/tolerances too demanding; etc.) }\end{array}$ & $\begin{array}{l}\text { Over-production (product designs generated faster than } \\
\text { testing capabilities, or overdesigned products) }\end{array}$ \\
$\begin{array}{l}\text { Transportation and movement (e.g. slow decision-making } \\
\text { process; too many data interfaces or multiple source; , etc.) }\end{array}$ & $\begin{array}{l}\text { Transportation (several hand-offs of information and } \\
\text { excessive need for approval) }\end{array}$ \\
$\begin{array}{l}\text { Unnecessary inventory (too much information; unnecessary } \\
\text { documents or prototypes) }\end{array}$ & $\begin{array}{l}\text { Inventory (queues of unprocessed information; sequencing } \\
\text { of design tasks) }\end{array}$ \\
$\begin{array}{l}\text { Waiting or delays (information created too early; lack of } \\
\text { information or unclear decision criteria; etc.) }\end{array}$ & Waiting (lack of resources or information) \\
$\begin{array}{l}\text { Inappropriate processing or poor NPD process design } \\
\text { (excessive meetings that lead to no results; too much } \\
\text { interaction; excessive testing and verification; failure to } \\
\text { identify and manage risk; etc.) }\end{array}$ & $\begin{array}{l}\text { Over-processing (late problem discovery leading to rework } \\
\text { and undesired design iterations) }\end{array}$ \\
$\begin{array}{l}\text { Unnecessary motion or inefficient performance of design } \\
\text { (lack of standardised processes; poor reuse leading to } \\
\text { unnecessary activities; inappropriate changes; etc.) }\end{array}$ & $\begin{array}{l}\text { Unnecessary movement (poor organization of data) } \\
\begin{array}{l}\text { Defects (warranty issues; use of immature technology; poor } \\
\text { make/buy decisions and supplier identification; etc.) }\end{array}\end{array}$ \\
$\begin{array}{l}\text { Defects (lack of understanding of customer needs resulting } \\
\text { in poor specifications) }\end{array}$ \\
$\begin{array}{l}\text { Underutilization of staff knowledge and skills (problems not } \\
\text { handled at the appropriate level in the organisation; } \\
\text { decisions taken without consulting local experts; customer } \\
\text { and employee feedback ignored in new designs). }\end{array}$ \\
\hline
\end{tabular}

From studying Table 5 it becomes apparent that waste in the LPD field has been strongly associated with inefficiencies in the product development process per se. All types of waste are to be avoided because they slow the process down and relate to activities that do not add value.

In GPD literature, the waste construct has a different meaning. Waste is mentioned in the literature as generated by industry at all stages of production, product use, and disposal (DeMendonca and Baxter, 2001). In particular, the GPD field views waste as strongly connected to the products being developed rather than the development process per se. GPD efforts have been extensively addressed towards improving products from an end-of-life management perspective (Santos-Reyes and LawlorWright, 2001). Lenox et al. (2000) report that one essential area of GPD activities is asset recovery, which induces a need to design products for take-back and ease of disassembly, reuse, and recycling to capture the value of products at the end of their useful life. Thus, initiatives such as Design for Disassembly (DfD), Design for Recycling (DfR), and Design for Remanufacturing (DfRem) have been considered to be key subareas of GPD (Mascle and Zhao, 2008; Pialot et al., 2012). The fundamental idea is that it will lead to minimisation of the amount of landfill waste and thus the dispersion of materials and substances from the techno-sphere. Although waste is strongly associated with the end-of-life phase of products, it is also associated with the other product life-cycle phases. Poor product designs are expected to cause waste in all phases. For example, improper product designs might lead to excessive machining of components or assembly failures during the manufacturing or 
remanufacturing processes. As a result, excessive materials are used. Another example refers to product designs that are not robust enough to withstand various user conditions and therefore need to be taken out of use earlier than expected. However, initiatives such as Design for Manufacturing and Assembly (DFMA) and Robust design are seldom addressed in the GPD literature.

Finding 4: In LPD, waste is strongly associated with the product development process per se and refers to activities that are non-value adding. GPD primarily considers waste to be of a physical nature and product-related. The overarching idea is to minimise the amount of waste going to recycling, incineration and landfill.

\subsubsection{Industrial application}

The number of industrial examples where LPD has been implemented and applied is not extensive. The examples mainly originate from the automotive industry (Liker and Morgan, 2006), but also from the aerospace industry (Haque and James-Moore, 2004). Clearly, there is bias towards practices at the automotive manufacturer Toyota (Hoppman et al., 2011). Thus, "empirical data on LPD remains fairly limited with most studies still having a strong focus on describing PD practices at Toyota or in aerospace organizations" (Letens et al., 2011 p. 82). There is still a lack of evidence regarding the applicability of LPD in different industrial sectors, even though authors such as Baines et al. (2006) argue that LPD presumably can be applied outside the automotive and aerospace sectors. Researchers have therefore called for more in-depth case studies in different industrial sectors to fully understand the applicability of LPD on a broader scale (e.g. Hoppman et al., 2011).

Literature on GPD does not present any restrictions regarding the industrial applications. GPD is assumed to be valid for all kinds of industry segments (Albino et al., 2012). Consequently, GPD efforts have been addressed towards various industry segments, such as the electronics industry (Boks and Stevels, 2007) and the automotive industry (Santini et al, 2010). The industry segments that have stricter legislation on restricted or banned materials, or where recycling and manufacturing are emphasised have been targeted by scholars. Others have adopted a more general perspective and tried to produce GPD insight that are not specific for certain industry segments (e.g. Luttropp and Lagerstedt, 2006).

Finding 5: Examples of LPD applications mainly originate from the automotive and aerospace industry segments, but it has been argued that LPD presumably can be applied in other sectors as well. GPD is considered to be relevant for all industry segments, but especially those industries that have strict legislation for material usage and/or high recovery rates.

\subsubsection{Implementation issues}

LPD implementation calls for an organisation-wide change in people and processes, as well as in the use of tools and techniques (León and Farris, 2011). A similar argument has been forwarded by Baines et al. (2006), who claim that successful implementation requires changes in systems, practices and behaviour. Wang et al. (2012) propose a step-wise procedure for implementation of LPD in companies. First, targets and scope of the transition should be defined. This includes, among other things, the identification of key activities in the product development process. Second, wastes occurring in the process should be identified. Third, tools/techniques are to be selected and implemented step-wise to support a lean development process. Finally, on the basis of the experienced gained from the initial changes, the entire product development organisation is 
changed. Thomas and Singh (2006) discussed implementation of the Design for Six Sigma (DFSS) tool/technique (presented in greater detail in a later section of this paper) and highlighted the appropriateness of starting with a pilot project to gain confidence in the tool/technique's effectiveness. Thereafter it can be integrated into the product development process on a more full scale. On the basis of a study at the Swedish bearing manufacturer regarding DFSS implementation, Hasenkamp and Ölme (2008) agreed that the tool/technique cannot be simply initiated and then expected to be used throughout the company. An important aspect to ensure continuous use was the institutionalisation of the tool/technique so that it became a common way of working.

Other scholars also advocate that implementation of LPD must be viewed from a long-term perspective. One of the few empirical studies of implementation of LPD in practice was carried out at the automotive manufacturer Ford by Liker and Morgan (2011). They found that the transformation to LPD required long-term commitment and a staging of the transformation process. The company relied upon a transformation model where the development process was changed in pieces via pilots. Lessons learned from these pilots were transferred to the organisational functions to lead from within. The transformation, and thus the organisational change, was then accelerated when the lessons learned were spread and tools/techniques added.

Although the example from Ford provides some insight into the transformation process to LPD, there are few examples from companies where LPD is applied (Hoppman et al., 2011). Arguably, the current knowledge regarding factors that affect the success or failure of LPD implementation is therefore scarce. León and Farris (2011), among others, call for more empirical studies so a balance is established between conceptual ideas and real LPD experiences. This is supported by Hoppmann et al. (2011 p. 3), who stress that "the implementation of the Lean PD components should be studied to identify factors and contingencies leading to their successful implementation".

Implementation issues are one of the heavily discussed topics in the GPD literature since many tools/techniques have been developed but few are used by industry. Boks and Stevels (2007) describe how GPD has emerged as a phenomenon proposed and researched by academic scholars in the early 1990s, and has since then starting to find its way to practitioners. Since the early days of GPD there has always been a drive to consolidate information and knowledge in the form of guidelines. Since the 1990s, companies have:

- moved forward;

- become acquainted with environmental issues;

- started with pilot studies; and

- learned to pick the low hanging fruit.

Implementation of GPD is related to different areas of concern as suggested by Johansson (2002): 1) management, 2) customer relationships, 3) supplier relationships, 4) development process, 5) competence, and 6) motivation. The areas of concern include 20 factors that are critical for implementing GPD. Examples of factors are: 1) a strong customer focus is adopted, 2) environmental issues are integrated into the conventional product development process, 3) environmental checkpoints, reviews and milestone questions are introduced into the product development process, 4) GPD is performed in cross-disciplinary teams, and 5) GPD support tools/techniques are used. The 
areas of concern and factors should be viewed from a holistic perspective, meaning that all should be considered simultaneously. Furthermore, it has been stated that when implementing GPD requirements from legislation and from the most important stakeholders, the entire product lifecycle must be analysed (Hauschild et al., 2004).

Others have emphasised that the GPD activities should be integrated in the daily product development work; especially the product design engineers need to view GPD activities as part of their routines (Gehin et al., 2008). In addition, Boks (2006) stated that the GPD research shows that companies perceive social, psychological and sometimes intangible processes that can "make or break" GPD implementation. Unwillingness to cooperate, gaps between GPD proponents and executors, and other organisational complexities play an important role. Two key factors for successful GPD are, according to Bovea and Perez-Belis (2012), the integration of environmental aspects into the early phases of the development process together with a multi-criteria approach that makes it possible to balance the environmental requirements against other traditional requirements.

In order to achieve better integration, companies could integrate GPD with their environmental management systems (EMS). Integrating GPD and EMS has many motives and ensures that a lifecycle perspective is adopted; in many cases products cause companies' main environmental impact (Ammenberg and Sundin, 2005a). In addition, integrating GPD and EMS makes the GPD activities a part of the continuous improvement efforts. By doing this the GPD activities become more integrated in the companies' overall environmental efforts (Ammenberg and Sundin, 2005a). The same authors have also found that the implementation of product issues in EMS is rather weak; most focus is put on manufacturing sites (Ammenberg and Sundin, 2005b). However, there are important product-related formulations identified in the ISO 14000 series. Guidelines for incorporating GPD into ISO 14001 were recently developed through the ISO 14006 guideline (ISO, 2011). Practically all production-oriented industries could benefit from the application of "green engineering" including all raw material producers, manufacturers, product users, recyclers, and waste handlers. To achieve this goal and become ISO 14000 certified, a more efficient and modern manufacturing require the application of GPD tools/techniques (DeMendonca and Baxter, 2001). By adopting and using the principles of GPD during the development of products and production processes, companies cannot only readily comply with ISO 14000 , but can also optimise energy and materials consumption while reducing waste, and, ultimately, environmental impacts (DeMendonca and Baxter, 2001).

By implementing environmentally responsible characteristics through GPD programs, employees, customers, and the world community benefit from a consistent approach to the environmental management of products. This leads to reaping the value of GPD that is both good for the environment and sound business sense (Donnelly et al. 2004; Donnelly et al. 2006). Furthermore, Donnelly et al. (2006) state that a product-based EMS, in contrast to location-based, addresses the impacts hardware products have on the environment. Product-based EMS appropriately aligns environmental issues with business drivers. This approach proved to be a successful alternative to implementing a stand-alone GPD initiative managed by the environment, health and safety organisation at a company studied by Donnelly et al. (2006). In the same area, Santos-Reyes and Lawlor-Wright (2001) identified a need for a structured approach to GPD that addresses environmental concerns in a coherent way. In addition, the same authors describe an organised 
process to address the problem of integrating environmental concerns into an early product development process that is consistent with ISO 14001.

According to Birch et al. (2012) and Short et al. (2012), there are a number of barriers to the adoption of GPD. Some of these barriers relate to the structure and presentation of the GPD tools/techniques. One of the most common issues is the lack of support and information offered by these tools/techniques when dealing with environmental issues in the product development process. Introducing environmental issues into product development process requires a trade-off between traditional product evaluation attributes and environmental ones (Berchicci and Bowedes, 2005).

Finding 6: Implementation of LPD should be viewed as a long-term step-by-step change process, involving organisation-wide changes in people, processes, and use of tools/techniques and techniques. Implementation of GPD rests upon a holistic perspective where various areas of concern should be considered and GPD can, for example, be integrated with companies' environmental management systems.

\subsection{Process}

This section outlines a comparison between the LPD and GPD concepts regarding the process dimension. First, issues related the process structure are discussed. This is followed by a comparison regarding when and how activities in the process are to be performed.

\subsubsection{Process structure}

As LPD essentially is focused on value creation and waste minimization, the product development process per se is at the core of the concept. The underlying idea is that structured and stable development processes help to produce predicable results (León and Farris, 2011; Welo, 2011). Process standardisation has consequently been viewed as one of the fundamental elements of the LPD concept (Liker and Morgan, 2006; Hoppman et al., 2011). "In product development, standardization implies maintaining a standard format or reporting system for information exchange and other routine tasks" (Nepal et al., 2011 p. 68). If reoccurring activities are standardised, their execution can be controlled even though development projects differ from case to case. Standardisation can lead to reduction of variability and development cycle times, increase in efficiency, minimization of the number of faults, and capture and management of knowledge, which supports continuous improvement (Ballé and Ballé, 2005; Liker and Morgan, 2006). It must be emphasised that the aim of standardisation is not to enforce discipline and a rigid structure of activities in the product development process (Welo, 2011). On the contrary, standardisation is used to avoid non-value adding activities and to allow for more experimentation and innovation. Means that can be used to achieve standardisation include checklists, standardised work instructions, design standards, standardised methods for problem solving, etc. (Ballé and Ballé, 2005; Liker and Morgan, 2006; Summer and Scherpereel, 2008; Hoppman et al., 2011). If these various means are constantly updated they become bearers of the current best-practice, and thus an instrument for learning and knowledge sharing that supports the continuous improvement of the product development capability.

The GPD literature has been less occupied with the structure of the product development process. The process has most often been assumed to be predefined into which GPD activities, tools/techniques, etc. are to be implemented. Major changes to the existing process should be 
avoided. Instead, scholars have suggested that GPD should be integrated into the existing process (Johansson, 2002; Ölundh-Sandström and Tingström, 2008; Albino et al., 2012). Often it is assumed that the process represents a linear stage-gate process (Johansson, 2006).

Finding 7: In LPD, standardisation of routines, activities, tools/techniques, etc. is expected to lead to structured and stable development processes that help to produce predicable results. GPD is suggested to be integrated into the existing process without any major changes to the process.

\subsubsection{Activities}

Another process-related issue outlined in the LPD literature is the need to apply the "pull principle" in the process (e.g. Haque and James-Moore, 2004). The principle refers to how the information is only to be produced by upstream activities if requested by downstream activities (Ballé and Ballé, 2005). In practice, the pull principle is not easily applied as it implies a need for defining the relevant information and sequence of activities a priori (León and Farris, 2011). Moreover, the LPD literature recommends that a levelled product development process flow is established (Liker and Morgan, 2006; 2011). A levelled flow supports the reduction of major changes in work load and thus eases the planning of activities. Information should be transferred in smaller batches, rather than accumulated into large ones (Yang and Cai, 2009; Gremyr and Fouquet, 2012). This resembles a Just-In-Time (JIT) approach, and as a result, information queues and development cycle time will be reduced accordingly.

The LPD literature also asserts that front-loading of activities is important to achieve a lean development process (Ballé and Ballé, 2005; Liker and Morgan, 2006). Early and thorough exploration of conceptual solutions, when there are few design space limitations, helps the development team to identify and solve anticipated problems. Set-based engineering, also known as set-based design, is an approach that allows a large number of design solutions to be produced in the early phases of the product development process, followed by a gradual reduction of the set of alternatives (Hoppman et al., 2011). The different design alternatives are tested and analysed in parallel, and those failing to fulfil the specified requirements are rejected (Liker and Morgan, 2006). It has been claimed in the LPD literature that set-based engineering is a fruitful approach, since time and resources invested early in the product development process significantly reduce uncertainty and thus the need for iterations in subsequent development phases (Balle' and Ballé, 2005). The performance of parallel activities, also denoted as simultaneous or concurrent engineering, has been advocated as important in the LPD literature (Hoppman et al., 2011). If activities overlap, instead of being performed in a sequence, development cycle time can be reduced.

GPD activities relate to all phases of the product development process (Johansson, 2002), and some researchers have proposed certain GPD activities and tools/techniques that should be used in individual phase of the process (Kaebernick et al., 2003). It has, however, been emphasised that major efforts should take place in the early product development phases (Gehin et al., 2008; ÖlundhSandström and Tingström, 2008), According to Choi et al. (2008), GPD activities should be performed early to ensure that the environmental consequences of a product's life-cycle are understood before manufacturing decisions are finalized. Applications of GPD principles in the first phases of the product development process can change a product life-cycle by not only reducing overall cost, but also the environmental impact of production, use and disposal. In line with this, Duflou et al. (2003) stated that the efficiency of GPD tools/techniques has yet to be limited by the need for detailed input 
data, typically unavailable in the early conceptual development phase, when most far-reaching improvements can be achieved. This might be a problem when designing one-of-a-kind products, where no information is available about previous product generations to guide the development efforts.

Finding 8: In LPD, the process flow is considered important to minimize waste, while the pull principle, front-loading of activities, set-based engineering and parallel activities are means to achieve a smooth flow. GPD activities relate to all product development phases, but it has been emphasised that major efforts should take place in the early phases.

\subsubsection{Performance metrics}

León and Farris (2011) state that one stream of LPD research can be classified as being performancebased. Performance metrics are defined to allow for assessment of goal fulfilment. As LPD focuses on creation of value for customers and avoidance of non-value adding activities during the product development process, performance metrics have been defined accordingly. Many metrics resemble the ones found in traditional "best practice" literature on NPD (e.g. Cooper and Kleinschmidt, 2007). Examples of LPD performance metrics include (Hoppmann et al., 2011): 1) adherence to schedule, 2) product and product development costs, 3) product quality, 4) revenues, and 5) market share. Evidently, the metrics cover efficiency as well as effectiveness aspects of the product development efforts. The metrics relate to both the product development process per se and the outcome in the form of the products and their success on the market. Letens et al. (2011) suggest a few performance metrics that can be used in an LPD context: 1) project throughput (the number of completed projects per year), 2) work-in-progress (the number of on-going projects), and 3) effort/development cycle time (the proportion of value-added time to total project duration). However, as the search continues among scholars for critical LPD performance metrics it is evident that a complete and agreed-upon list of critical measures is still absent (León and Farris, 2011).

At a high level, a performance metric within the GPD field is the Dow Jones Sustainability index. According to Albino et al. (2012) there are 255 companies listed on the Dow Jones Sustainability index, which operates throughout the world and includes several types of industries. At a more detailed level, GPD focuses on the environmental impacts of products related to their life cycles. Different life-cycle analysis (LCA) tools/techniques allow the use of different metrics such as noise, energy use, toxicity, recyclability, etc. (Zhang et al., 2011). Park and Seo (2006) have developed a tool/technique to assess the environmental impacts of product design alternatives, which is in line with the method developed by Song and Lee (2010) that indicates different design alternatives' greenhouse gas emissions or $\mathrm{CO}_{2}$ equivalents. The method by Song and Lee (2010) starts by setting the targets for greenhouse gas emissions, and then the materials and components are chosen to reach those targets. Others have tried to combine environmental impact metrics with economic metrics. Bevilacqua et al. (2007) have developed a GPD framework which includes an improvement cycle which identifies the environmental and economic break-even point (BEP) between two product design solutions. In addition, Boks and Stevels (2007) state that there are three different perspectives of "what is green" among the different stakeholders involved in GPD, namely scientific green, government green and customer green. All these perspectives should be considered in order to truly achieve GPD. Performance metrics should therefore reflect all three perspectives. 
Finding 9: In LPD, performance is measured as both efficiency and effectiveness of the product development effort. Many metrics resemble those found in traditional "best practice" literature on NPD. In GPD, several metrics are used to measure environmental performance; a common metric is the greenhouse gas metric or the $\mathrm{CO}_{2}$ equivalent metric. Attempts have been made to combine environmental impact metrics with economic metrics.

\subsection{People}

This section compares the LPD and GPD concepts regarding the people dimension. First, issues related to competencies deemed important for each concept are presented, followed by a comparison regarding organisation as well as learning and training issues.

\subsubsection{Competencies}

Technical excellence is heavily emphasised as a fundamental ingredient of LPD. Liker and Morgan (2006) assert that engineers need to have deep, specialised knowledge in different engineering disciplines. Specialist competencies are emphasised where engineers stay for an extensive period in their functional organisations, and on-the-job training is considered important to stimulate technical expertise and standardized skills (Hoppman et al., 2011). Therefore, specialist career paths are important where engineers have strong connections to their organisational functions. This allows their knowledge and expertise to be nurtured among specialists within the same disciplines. Within the functions, the engineers can continuously gather and share knowledge and best practices among peers (Haque and James-Moore, 2004). Within the LPD literature there is a consensus that the strong leadership of an expert chief engineer is key for prosperous product development (Baines et al., 2006). The chief engineer is a heavyweight project manager who acts as the leading architect, with conclusive authority and responsibility for the entire product development project (Liker and Morgan, 2006). This involves strong involvement in the technical details (Hoppman et al. 2011), but also acting as the "voice of the customer" during the project to ensure that the product specification is translated into goals which are aligned with the various functions involved (Haque and JamesMoore, 2004). Other responsibilities of the chief engineer include making make sure that the project adheres to the project schedule, cost, and performance goals established for the project.

The GPD tools/techniques are targeted to be used by the product development teams and mainly the product design engineers. Those engineers, who decide many things about the product design that directly influence the environmental performance of products, use GPD tools/techniques to facilitate communication about environmental issues in the product development process (Lindahl, 2006). In addition, the literature has asserted that environmental specialists might play a central role in the GPD activities (Johansson and Magnusson, 2006). Their deep knowledge of environmental issues are likely helpful for a product development team when searching for low-impact solutions. Furthermore, it has also been stated that an environmental champion, who emphasises the importance of environmental concern, can support the GPD work (Johansson, 2002). This is supported by Berchicci and Bodewes (2005) who claim that it is important to involve people in the product development team that act as champions. The project manager, who has responsibility and control of a product development project, also constitutes an important actor (Johansson, 2006). 
Finding 10: LPD emphasises the need for technical excellence in different engineering disciplines and the key role of the chief engineer who leads the development project. GPD emphasises the roles of product design engineers, environmental specialists, environmental champions and project managers to ensure consideration of environmental issues in a product development project.

\subsubsection{Organisation}

According to Liker and Morgan (2006), Toyota is basically a functionally organised company were engineers report to the functional managers in their discipline. This reflects the strong LPD focus on technical expertise. Functional managers have solid technical knowledge and act as teachers and mentors to the engineers. However, as co-ordination is an inherent need in product development, cross-disciplinary integration is also emphasised in the LPD literature (Letens et al., 2011). Thus, to find an appropriate balance between specialisation and co-ordination the matrix organisation is advised in development projects (Anand Kodali, 2008; León and Farris, 2011; Wang et al. 2011). Based on an analysis of the use of teams in NPD, Saranga (2011) found that the use of multiple development teams (for example, when performing set-based engineering) was beneficial in terms of improved quality due to the higher degree of flexibility. Furthermore, as argued by Welo (2011), the culture in an LPD organisation should reflect an "all the people all of the time" culture where facts are used to create value. One of the most important factors for creating value is the culture of awareness among all those involved in product development. For example, Toyota has made the "customer-first" value a part of the culture of the company (Liker and Morgan, 2006). When conflicts of interest occur among engineers involved in a product development project (e.g. among design engineers and manufacturing engineers), the overall goal of providing customer value is emphasized. Then, the necessary compromises are specified with the customer in mind.

The GPD literature have addressed organisational issues, but not to the same extent as tools/techniques have been treated. This is indicated by Baumann et al. (2002) who claim that too little research has been addressed to the large context of product development. In general, the literature assets that GPD is best performed in cross-disciplinary teams (Johansson, 2002). Such product development teams allow environmental issues to be considered along with other essential issues. One study that focused specifically on how to organise for environmental concern in product development was done by Johansson and Magnusson (2006). They found that the inclusion of a specific "green" sub-project in the project organisation can: 1) serve as a means to ensure that environmental issues are put on the agenda, 2 ) introduce a risk for confusion regarding who is responsible for fulfilling the environmental performance requirements, 3) act as an arena for communication about the environmental performance requirements, 4) serve as a platform for environmental champions to be active, and 5) serve as a means for environmental specialists to become part of established contact networks in the product development organisation.

Still, organising for GPD might is challenging. Boks (2006) reported that one obstacle is organisation complexities, which might hamper communication and collaboration. Soylu and Dumville (2001) argue in a similar vein and claim that an organisational problem is that the lack of interaction and collaboration among cross-disciplinary teams brings a degree of risk and uncertainty, which might result in detrimentally affecting organisational sustainability. Managers should develop procedures dealing with communication in cross-disciplinary teams. There are different ways of dealing with organisational issues as well as the previously mentioned ways of dealing with implementation issues. Ammenberg and Sundin (2005a) state that standardised EMS have the potential to remove 
the barrier of GPD being limited to single events by establishing an organisational structure where procedures for the inclusion of environmental criteria are facilitated, and such procedures are made permanent rather than stand alone. Another approach would be to explore the role of suppliers in enhancing the company's ability to successfully carry out GPD. Lee and Kim (2011) found that there is a strategically close relationship of environmental collaboration between suppliers and the buying company through technological integration, and that involving key suppliers in GPD can bring both environmental and commercial success. In addition, Hoffman (2007) has found user involvement favourable in GPD in the tool called "innovating through consumer-integrated product development" (INNOCOPE).

Finding 11: The functional organisation plays a central role in LPD, where co-ordination is achieved by devising a matrix organisation in the development projects. GPD is preferably carried out in crossdisciplinary product development teams.

\subsubsection{Learning and training}

Continuous improvement is at the heart of the lean concept. In a product development context this implies constant learning and training to improve development capacity (Liker and Morgan, 2006). LPD organisations rely on learning and training via the relationships between managers, supervisors, and workers (Nepal et al., 2011). Engineers are seldom told exactly what to do, but guided through questions from their managers or supervisors. This encourages the engineers to think about the problem and find the root causes, which is essential in the search for identifying the appropriate solution to a problem. Schulze and Störmer (2012), in their study of 108 companies located in Germany, Switzerland and Austria, found evidence that employee training and coaching are important management means to achieve LPD. The empirical data showed that training in the lean concept (e.g. lean thinking, waste analysis, standardization, etc.) helped to identify and eliminate waste in the product development process. The study also revealed that coaching, where senior managers acted as advisors to teach novices, was beneficial. Coaching tended to empower individuals and teams to generate results by creating a stimulating organizational climate. Intensive communication was found to be central in the coaching activities. The practical implications from the study were that senior managers cannot only rely on technical skills; it is also essential that they possess excellent teaching and mentoring skills.

The importance of learning and training has been manifested in the GPD literature. In his review of GPD literature, Johansson (2002) found that providing education and training to product development personnel was one of the success factors for implementing GPD in a company. Education and training can be related to general environmental education for all personnel, including product development team members and individuals working in the functional organisation. This might be an important factor for increasing a company's awareness of the link between the company's activities and the environmental impact. Education and training can also be targeted more specifically towards the specific needs of the different product development team members. An example is product design engineers' training in using different tools/techniques. On a more generic level, universities have a responsibility to ensure that their education programs fit with industry needs. Therefore, many universities are developing new courses in product life-cycle engineering and environmentally conscious product development and manufacture (Jawahir et al., 2007). 
Finding 12: LPD asserts the importance of learning and training to achieve continuous improvement in the product development process. GPD also emphasises that learning and training must be provided to all product development personnel to ensure that environmental issues are considered in the product development process.

\subsection{Tools/techniques}

This section compares the LPD and GPD concepts regarding tools/techniques. First, the number of tools/techniques is described, followed by a comparison between the types of tools/techniques advocated in the literature.

\subsubsection{Number of tools/techniques}

Tools/techniques have been considered central in the LDP concept. However, it has been argued that it would be a mistake to think that the mere introduction of such tools/techniques would lead to lean product development processes. The tools/techniques need to be carefully selected and used wisely, and must fit with the system perspective of LPD (Liker and Morgan, 2006). The literature offers an extensive number of different tools/techniques to be used as part of the LPD concept. For example, Haque and James-Moore $(2002 ; 2004)$ mention 28 different tools/techniques that are enablers for the attainment of LPD processes. Similarly, Anand and Kodali (2008) provide an even longer list that contains 38 different tools/techniques which are claimed to be required for LPD. Despite the rather extensive number mentioned in the literature, there does not seem to exist any commonly agreed upon list of such tools/techniques. Rather, the different tools/techniques mentioned by scholars are based on their belief regarding which are relevant as part of the LPD concept.

Many tools/techniques have been developed for GPD, although few have made a significant breakthrough in industry (Bevilacqua et al. 2007). Many researchers, including Luttropp and Lagerstedt (2006), Mascle and Zhao (2008), Simon et al. (2000), Maxwell and van der Vorst (2003), Maxwell et al. (2006), Müller (2012), Smith and Yen (2010), Tseng et al. (2008), Vercalsteren (2001), Vinodh (2010), Vinodh and Rathod (2010 and 2011), Yang and Chen (2011), and Zhang et al. (2011) have evaluated several GPD tools/techniques and then developed yet another one of their own. Therefore criticism has been raised that too many tools/techniques have been developed and that researchers within the GPD field are more interested in developing a new tool than on studying the use of existing ones and to evaluate them in order to improve them (Baumann et al., 2002). The large number of tools/techniques is indicated by Birch et al. (2012) who investigated 22 GPD tools/techniques developed from 1997 to 2009 from academia and industry. Other examples that show the magnitude and types of GPD tools/techniques are found in the literature: Ljungberg (2007) presents a GPD tool/technique to suggest which kinds of materials to choose in product design; Poudelet et al. (2012) propose a GPD tool/technique that includes LCA data and thus using LCA as a predictive tool/technique rather than a retrospective tool/technique; and Sakao (2009) has developed a classification framework and suggests that there is potential for using quality engineering tools/techniques to deal with customer perception in the early phase of GPD. Choi et al. (2008) stated that many computer-based LCA tools/techniques exist for assessing the environmental performance of products. However, there are no tools/techniques that integrate both LCA and multicriteria decision-making for the selection of GPD analysis. Therefore, the link between LCA and decision-making is weak (Choi et al., 2008). In addition, scholars have emphasised that the product 
design engineers must put correct requirements on the GPD tools/techniques in order to make them more useful (Lindahl, 2006).

Finding 13: The literature offers several different tools/techniques to be used as part of the LPD concept, but no commonly agreed upon list of tools/techniques exists. An excessive number of tools/techniques have been developed for GPD, although few have made a significant breakthrough in industry.

\subsubsection{Types of tools/techniques}

The preceding section identified that the use of tools/techniques is considered to be an essential ingredient of the LPD concept. However, a precise definition of what constitutes a tool/technique is not given in the literature. It is, therefore, unclear what a tool/technique actually is. Still, many different types are presented in the literature, with various suggestions for their use, as exemplified in Table 6 below:

Table 6: Examples of LPD tool/technique types.

\begin{tabular}{|c|c|}
\hline Anand and Kogali (2008) & Wang et al. (2011) \\
\hline $\begin{array}{l}\text { Information technology-supported tools/techniques } \\
\text { (computer-aided engineering, design and manufacturing } \\
\text { systems (CAE/CAD/CAM), product data management (PDM) } \\
\text { software, E-mail systems, rapid prototyping techniques, etc.) }\end{array}$ & $\begin{array}{l}\text { Experience for design collection and feedback } \\
\text { tools/techniques. }\end{array}$ \\
\hline $\begin{array}{l}\text { Product design, development and management } \\
\text { tools/techniques (quality function deployment (QFD), failure } \\
\text { mode effect analysis (FMEA), quality engineering/Taguchi } \\
\text { tools/techniques, design of experiments (DoE), set-based } \\
\text { engineering, standardisation, etc.) }\end{array}$ & Product design, development tools/techniques. \\
\hline $\begin{array}{l}\text { Organisation-based tools/techniques (co-location, cross- } \\
\text { disciplinary teams, concurrent engineering, empowerment, } \\
\text { use of heavyweight team structure, etc.) }\end{array}$ & Chief engineer and organization tools/techniques \\
\hline
\end{tabular}

Even though the literature shows inconsistency regarding what should be considered to be an LPD tool/technique, there is evidence that the use of tools/techniques is an important means in the strive for product development success. For example, Sun et al. (2009) found that the use of various tools/techniques led to a faster product development process.

As LPD focuses strongly on customer value creation, researchers advocate the need for establishment of clear links between customer demands and product properties. The potential of the QFD tool/technique for helping product development teams to ensure the voice of the customer has been addressed in the LPD literature. According to Chen (2010), QFD is an enabler for companies to achieve high quality and to ensure fit between customer needs and product performance. QFD is useful for improving process management, among other things, because it supports extensive communication and employee involvement. Another tool/technique that has gained some attention in the LDP literature is the application of visual management (Hines et al., 2006). In their study of four companies applying visual planning, Lindlöf and Söderberg (2011) found that tools/techniques supported efficient communication and shared understanding to be established among the engineers. It further supported the ability to prioritise tasks and to level out workloads. However, 
they also found that when development teams are geographically dispersed it limited the use of the visual planning. Several approaches can be part of the visual management tool/technique, such as the use of A3 reports, the obey system (big room), "pulse" meetings, etc. (Liker and Morgan, 2006; León and Farris, 2011; Letens et al., 2011; Gremyr and Fouquet, 2012). A3 reports are used for three different purposes: 1) knowledge sharing, 2) problem solving, and 3) project status reporting (Yang and Cai, 2009).

Another tool/technique that is strongly related to the LPD goal of producing customer value is the value engineering (VE) approach, which focuses on "elimination of all unnecessary cost elements, ones that provide no benefits to the user or other stakeholders throughout the product lifetime, rather than providing the necessary functions at the lowest possible cost" (Welo, 2011 p. 324). The VE approach is often associated with the target costing tool/technique, which represents a feed-forward mechanism that the development team can use to modify the design of a product to reduce costs, while maintaining a desired level of product properties such functionality and quality (Cooper and Slagmulder, 2004). Another costing tool/technique is product-specific kaizen costing. This can be used for rapid redesign of a product during the early phase of manufacturing to correct for any cost overruns (ibid.). The theory of inventive problem solving (TRIZ) has been suggested as one tool/technique that can be used as a support for generating ideas for improvement (Shirwaiker and Okudan, 2006). An additional tool/technique that has been advocated in the LDP literature is the integration of suppliers. As suppliers in many cases provide much of a product's content, it is important that companies manage and encourage suppliers in the same way as internal manufacturing and engineering resources (Liker and Morgan, 2006).

Design for six sigma (DFSS) has been considered by some researchers to be a specific approach to product development including a set of tools/techniques (Johnson, 2006; Chung and Hsu, 2010; Hasenkamp, 2010; Jou et al., 2010), whereas others see it as one of the tools/techniques associated with LPD (Antony, 2002; Wang et al., 2011). In studies of interrelationships between DFSS and LPD it was found that there are a number of connections between the two concepts (Fouquet, 2007). At the very heart of both concepts is the reduction of waste and improvement of quality. Thus, Gremyr and Fouquet (2012) argued that merging the concepts would be beneficial, even though some differences should be considered when implemented in industrial practice. Whereas the DFSS concept focuses on the product per se to a higher degree, it can certainly be combined with the LPD focus on the speed and flow of the product development process. Or, as stated by Yang and Cai (2009 p.97): "DFSS improves product value and product quality, whereas LPD improves product development lead time, efficiency, flexibility and product development cost."

A large number of GPD tools/techniques have been developed. Baumann et al. (2002) divide the tools/techniques into six different categories: frameworks, checklists and guidelines, rating and ranking tools/techniques, analytical tools/techniques, software and expert systems, and organising tools/techniques. In addition, Bovea and Perez-Belis (2012) have characterised several GPD tools/techniques developed during recent years. Their paper reviews and classifies GPD tools/techniques and how they are integrated into the product development process. The tools/techniques range from general to specific tools/techniques that which focus on parts of the life-cycle or on certain types of products and services (Hauschild et al. 2004). For example, Brissaud and Zwolinski (2004), Sundin and Bras (2005), ljomah et al. (2007), Gehin et al. (2008), Mathieux et al. (2008), Pigosso et al. (2010), Pialot et al. (2012) and Sundin et al. (2012) have developed 
tools/techniques and principles to facilitate end-of-life process, including product remanufacturing and/or material recycling. Furthermore, Bevilacua et al. (2007) have developed a framework, based on LCA thinking, which allows the integration of environmental parameters directly into the design of products and processes. Through this framework, GPD serves as an environmental decision-making support for designers. In line with this, Choi et al. (2008) have developed a tool/technique that integrates both quantitative and qualitative data in the decision-making process to prioritise alternative GPD strategies.

Finding 14: LPD is supported by the use of various tools/techniques. Some have a product-oriented focus where quality is at the core, whereas others address efficiency and improvement of the product development process per se. Many different types of GPD tools/techniques have been developed with different focus on, e.g., reducing environmental impacts and facilitating end-of-life processes.

\section{Propositions that reflect potential cross-field learning between LPD and GPD}

Based on the comparison of literature within the LPD and GPD fields, nine propositions are suggested. These propositions reflect the potential for cross-field learning and hence also indicate potential synergies between the LPD and GPD concepts. The propositions are related to the dimensions and different sub-categories used for the comparison between LPD and GPD as shown in table 4.

The value construct in the LPD literature is strongly associated with the customer perspective. In the end it is the customer who decides whether value has been produced in the NPD process when he or she decides to buy a product. The GPD literature also discusses the customer as an important stakeholder, but more as a user of a product than someone making a decision to buy a product. The motives/drivers for companies to engage in GPD are strongly associated with legal compliance and reduction of environmental impacts. Still, it has been asserted in the literature that strong customer focus is a prerequisite for successful implementation of GPD in companies (Johansson, 2002). If a stronger customer focus is adopted, the competitive advantages might be more apparent for a company (Short et al., 2012). In comparison to the value construct in the LPD field, the GPD field adopts a broader perspective on value. The intention is to develop products that have low environmental impact, which is beneficial not only for the customers buying the products but also for society in general. If the value construct as viewed in the LPD field is expanded to also include benefits for society in terms of reduced environmental burdens, it can be assumed that the argument for LPD implementation increases. Likewise, if the GPD value construct incorporates a stronger focus on providing customer value the motive for GPD implementation is stronger. This leads to the following propositions:

$\mathbf{P}_{1 \mathrm{a}}:$ A stronger focus on value creation for customers, as advocated in $L P D$, is positively associated with GPD implementation.

$\mathbf{P}_{1 \mathrm{~b}}$ : Adoption of a broader customer definition, that also includes potential advantages for society in general, as in GPD, is positively associated with LPD implementation. 
The waste construct is treated differently in the LPD and GPD literature. In LPD, waste is considered to be inherent in the product development process in the form of non-value adding activities. Waste reduction as advocated in the LPD literature is therefore aimed at improving the speed and efficiency of the product development process (Haque and James-Moore, 2004; Gautam et al., 2007; Anand and Kodal, 2008). In GPD, waste is viewed to be of a physical character related to the products' lifecycles. Waste reduction in GPD focuses strongly on minimising the environmental loads associated with products and preservation of natural resources (Santos-Reyes and Lawlor-Wright, 2001). The waste construct can hence be viewed as "internally-oriented" in LPD and "externally-oriented" in GPD. If the LDP waste construct is more clearly related to inefficiencies that cause environmental impacts, for example in the form of excessive materials usage, the argument for LPD implementation becomes stronger. Similarly, if the GPD waste construct also incorporates "internally-oriented" waste where non-value adding activities are minimised the motive for GPD implementation is stronger. The propositions below are therefore stated:

$\mathbf{P}_{2 \mathrm{a}}$ : An extension of the focus on an "internally-oriented" waste construct to also include "externallyoriented" waste, as advocated in GPD, is positively associated with LPD implementation.

$\mathbf{P}_{2 \mathrm{~b}}$ : An extension of the focus on an "externally-oriented" waste construct to also include "internallyoriented" waste, as advocated in LPD, is positively associated with GPD implementation.

Scholars in the LPD field maintain that LPD implementation calls for a holistic perspective where the process-people-tools/techniques dimensions are considered. Each of the dimensions is dependent on the others and cannot be viewed in isolation. For example, implementing the tools/techniques dimensions without having a proper product development process in place will definitely lead to failure. People also need teaching and training in new tools/techniques, and therefore these two dimensions are tightly coupled. The three dimensions (process-people-tools/techniques) must hence be viewed as a system if LPD is to be successfully implemented (Liker and Morgan, 2011).

The GPD literature also advocates the need for a holistic view when implementing the concept in a company. For example, Johansson (2002) identified 20 success factors for implementing GPD. The factors relate to all three process-people-tools/techniques dimensions. Arguably, a systems perspective should preferably be adopted when GPD is implemented. Thus, the following proposition is outlined:

$\mathbf{P}_{3}$ : The adoption of a systems perspective that includes the process-people-tools/techniques dimensions is positively associated with successful implementation of both LPD and GPD.

The LPD literature asserts that the product development process per se should be improved. Ultimately, this is assumed to lead to a reduction of waste and better provision of customer value. Standardisation is seen as one means to ensure that unnecessary activities are avoided in the product development process. That is, current best practices are implemented as standards and used to guide product development (Ballé and Ballé, 2005; Liker and Morgan, 2006). However, standardisation is not aimed at leading to a rigid product development process, but merely to avoid that non-value adding activities are done (Welo, 2011). The GPD literature, on the other hand, most often views the product development process as predefined into which GPD activities, tools/techniques, etc. should be integrated. However, adding "more" activities, tools/techniques, etc. to the product development process to achieve better products from an environmental 
perspective might be considered to increase the amount of waste from an LPD perspective, if there is no clear link to customer value. Still, the standardisation advocated in the LPD literature might be supportive for the implementation of GPD. If the product development process is clearly defined and activities standardised, then it might be easier to see where the GPD activities and tools/techniques fit and thus GDP can be anchored into the process. Therefore, the proposition below is presented:

\section{$\mathbf{P}_{4}$ : Increased standardisation, as advocated by $L P D$, is positively associated with GPD implementation.}

Both fields present different metrics that are considered to be meaningful to measure the results of the LPD and GPD efforts. However, whereas LPD metrics resemble those that appear in traditional "best practice" literature on NPD, GPD metrics are strongly related to the environmental performance of a product during its entire life-cycle. These two sets of performance metrics are not mutually exclusive, but rather complementary. Thus, in order to be able to address both lean and green issues in product development it might be fruitful to merge these two types of metrics into a combined and coherent set of performance metrics. The proposition below is hence stated:

\section{$\mathbf{P}_{5}$ : The implementation of both LPD and GPD is positively associated with the development of a combined and coherent set of performance metrics.}

Both literature fields argue that learning and training are essential means to initiate and carry out the organisational changes needed to become LPD and GPD organisations. In the LPD literature it has been found that training in the lean concept has helped to identify and eliminate waste in the product development process. Nepal et al. (2011) claim that LPD organisations focus strongly on learning and training. Relationships between managers, supervisors, and workers are key for this learning and training to take place. Schulze and Störmer (2012) also argue that employee training and coaching are central in becoming an LPD organisation.

The GPD literature showed that it is essential to improve the product development personnel's skills in order to successfully implement GPD in a company. Johansson (2002), for example, found that providing education and training to the product development personnel is one of the key success factors for GPD implementation. Likely, there will be no conflict if learning and training include both lean and green issues concurrently. Therefore, the following proposition is suggested:

\section{$\mathbf{P}_{6}$ : Learning and training that concurrently address both lean and green issues are positively associated with implementation of both the LPD and GPD.}

The use of tools/techniques is an inherent part of LPD and GPD. There exist a wide range of different tools/techniques in both fields. However, they have been developed for specific purposes and thus the number of tools/techniques is extensive. Research has also revealed that many of the tools/techniques are not implemented in industrial practice (e.g. Baumann et al., 2002). One reason might be that companies find it hard to use a large number of stand-alone tools/techniques. Hence, from an industrial perspective it would seem preferable if LPD and GPD tools/techniques were combined and integrated into a limited number of tools/techniques.

\section{$P_{7}:$ The combination and integration of LPD and GPD tools/techniques into a limited number is positively associated with LPD and GPD implementation.}


In Table 7 the propositions presented above are summarised.

Table 7: Propositions indicating cross-field learning between LPD and GPD.

\begin{tabular}{|c|c|c|c|}
\hline No. & Proposition & Dimension & Sub-category \\
\hline P1a & $\begin{array}{l}\text { A stronger focus on value creation for customers, as advocated in } \\
\text { LPD, is positively associated with GPD implementation. }\end{array}$ & General & The value construct \\
\hline P1b & $\begin{array}{l}\text { Adoption of a broader customer definition, that also includes } \\
\text { potential advantages for society in general, as in GPD, is positively } \\
\text { associated with LPD implementation. }\end{array}$ & General & The value construct \\
\hline P2a & $\begin{array}{l}\text { An extension of the focus on an "internally-oriented" waste } \\
\text { construct to also include "externally-oriented" waste, as } \\
\text { advocated in GPD, is positively associated with LPD } \\
\text { implementation. }\end{array}$ & General & The waste construct \\
\hline P2b & $\begin{array}{l}\text { An extension of the focus on an "externally-oriented" waste } \\
\text { construct to also include "internally-oriented" waste, as advocated } \\
\text { in LPD, is positively associated with GPD implementation. }\end{array}$ & General & The waste construct \\
\hline P3 & $\begin{array}{l}\text { The adoption of a systems perspective that includes the process- } \\
\text { people-tools/techniques dimensions is positively associated with } \\
\text { successful implementation of both LPD and GPD. }\end{array}$ & General & Implementation issues \\
\hline P4 & $\begin{array}{l}\text { Increased standardisation, as advocated by LPD, is positively } \\
\text { associated with GPD implementation. }\end{array}$ & Process & Process structure \\
\hline P5 & $\begin{array}{l}\text { The implementation of both LPD and GPD is positively associated } \\
\text { with the development of a combined and coherent set of } \\
\text { performance metrics. }\end{array}$ & Process & Activities \\
\hline P6 & $\begin{array}{l}\text { Learning and training that concurrently address both lean and } \\
\text { green issues are positively associated with implementation of both } \\
\text { the LPD and GPD. }\end{array}$ & People & Learning and training \\
\hline P7 & $\begin{array}{l}\text { The combination and integration of LPD and GPD tools/techniques } \\
\text { into a limited number is positively associated with LPD and GPD } \\
\text { implementation. }\end{array}$ & Tools/techniques & $\begin{array}{l}\text { Types of } \\
\text { tools/techniques }\end{array}$ \\
\hline
\end{tabular}

\section{Discussion and conclusions}

As the current knowledge of potential synergies, conflicts, or overlaps between LPD and GPD is poor, the idea of this paper has been to illuminate differences and similarities between the two concepts in order to reveal potential conflicts, synergies, or overlaps. The comparison shows that the differences between the LPD and GPD concepts lie in: their goal and focus, value construct, process structure, performance metrics, and tools/techniques used. Still, the comparison summarised in table 4 indicates that there are synergies between the concepts. Basically, LPD and GPD are driven by a search for increased competitiveness. LPD emphasises that enhanced competitiveness is gained by reduction of development and product costs, higher product quality, improved revenues and market shares. Compliance with regulations and legislation is a also strong driver for GPD as there are some doubts regarding the potential commercial benefits. 
Although the value construct is different in the two concepts, they do not seem to be conflicting. On the contrary, extending the value construct to include a broader customer definition where both customers who buy the products and society are included might motivate companies to engage in both LPD and GPD implementation. Both concepts target waste reduction. However, what is considered waste differs between the concepts. Whereas LPD focuses on waste in terms of unnecessary and non-value adding activities, GPD addresses waste that is of a physical nature in order to save natural resources and reduce materials that are sent to recycling, incineration and landfill. Combining these two types of wastes might enhance the opportunity for further waste reduction, as indicated by one of the propositions presented in the previous section. It is, however, important to be aware of the potential conflict between the concepts regarding the waste construct. Adding GPD activities and tools/techniques to assess and improve the environmental performance of products might be considered increased waste from an LPD perspective. If the activities cannot be clearly related to added value, then it might be hard to argue that GPD activities should be performed.

None of the concepts present limitations regarding industrial applicability. LPD applications reported in the literature are mainly from the automotive and aerospace industry segments. Industrial application of GPD can be found in the automotive and electrical and electronics industry segments. The GPD applications have, to a large extent, been driven by regulations and legislation targeted towards those industry segments. Implementation issues are considered vital in both concepts and rest upon a systems perspective where the dimensions of process-people-tools/technology are linked holistically. Omitting any of the dimensions will likely lead to implementation failure. As indicated by one of the propositions, the need for a systems perspective indicates that there are opportunities to simultaneously implement the two concepts.

Due to their different focus, different performance metrics are used in the LPD and GPD concepts. However, it has been suggested that GPD performance metrics should also include economic metrics in addition to the traditional environmental impact metrics. This indicates a potential to define performance metrics that results in a combined and coherent set of metrics that addresses both LPD and GPD concepts.

LPD and GPD share similarities regarding the people dimension, including competence and organisation as well as learning and training. Both concepts highlight the need for specific competences. Whereas the LPD concept is strongly associated with technical excellence in different engineering disciplines and the role of the chief engineer, GPD emphasises the roles of product design engineers, environmental champions and specialists, and project managers. Involvement of skilled personnel is hence at the core of both concepts. Furthermore, LPD underscores the role of the functional organisation, but also that the matrix organisation structure is used to ensure coordination. Similarly, the GPD literature asserts that the GPD activities should be carried out in cross-disciplinary teams where the environmental competence is included to ensure concern for the environmental issues. To achieve the necessary skills and to ensure that the concepts are implemented and applied in companies, both concepts assert the need of learning and training. It should be possible to concurrent LPD and GPD learning and training, as indicated by one of the propositions outlined in the previous section. 
The use of different tools/techniques is an inherent ingredient in both LPD and GPD. However, as the concepts have different goals tools/techniques have been suggested. This has resulted in numerous tools/techniques, especially in the GPD field. Evidence shows that rather few GPD tools/techniques have been implemented and used in practice. However, as the use of tools/techniques play a central role in both concepts there should be synergies if the tools/techniques can be combined and integrated into a reduced number. This might simplify the implementation and use in practice.

This paper asked the question of whether LPD and GPD are two sides of the same coin. As has been indicated in the comparison between the concepts, there seems to be a number of synergies even though difference exist. As there are some differences between the concepts it cannot be argued that they are two sides of the same coin, meaning that LPD automatically leads to greener products or that GPD ensures improvements and efficiency in the product development process.

Consequently, the review of literature does not unambiguously support that "green thinking is thinking lean" as was stated in the outset of the paper. However, if the analogy to money is further used it is reasonable to conclude that LPD and GPD belong to the same "currency". That is, the concept share a number of similarities that indicate a synergistic relationship. This synergistic relationship has been accentuated by the propositions outlined in the previous section where the potential for cross-field learning is shown.

As the study presented in this paper shows, there is potential for cross-field learning between the LPD and GPD fields. Therefore, future research should adopt a more integrated approach to study LPD and GPD. Despite their differences, it would be valuable to study in more detail what the LPD and GPD research fields can learn from each other, and if an integrated concept that includes both the LPD and GPD concepts can be developed. From an industrial practice perspective, it would definitely be beneficial if the concepts could be merged. Companies could then avoid the drawback of implementing two "new" concepts in the product development organisation. Instead, one integrated concept could be implemented where both lean and green issues are considered. A number of potentially interesting research directions are indicated by the propositions presented in the previous section.

Furthermore, the literature has offered fairly poor evidence regarding the industrial applicability of LPD and GPD. Evidently, the amount of literature that presents conceptual ideas is quite extensive in both fields. A potential explanation might be that research in both fields is still relatively novel, compared to the main body of NPD literature. Empirical studies of LPD and GPD practice were quite rare in the reviewed literature. In the LPD literature, several conceptual frameworks appeared and the GPD literature presented numerous tools/techniques. However, both fields suffer from "real world" studies where the concepts have been applied in practice. Therefore, scholars have called for more empirical studies, including both case studies and surveys (Baumann et al., 2002; Hoppman et al., 2011; Letens et al., 2011). This seems to be a common notion in both research fields. Future research should thus address implementation of LPD and GPD in practice, preferably when the two concepts are implemented in an integrated manner. 


\section{References}

Albino, V., Balice, A., Dangelico, R.M., lacobone, F., 2012. The Effect of the Adoption of Environmental Strategies on Green Product Development: A Study of Companies on World Sustainability Indices, International Journal of Management, 29 (2), 525-538

Ammenberg, J., Sundin, E., 2005a. Products in environmental management systems: drivers, barriers and experiences, Journal of Cleaner Production, 13 (4), 405-415.

Ammenberg, J., Sundin, E., 2005b. Products in environmental management systems: the role of auditors, Journal of Cleaner Production, 13 (4), 417-431.

An, V., 2001. Integrating the ecodesign concept in small and medium-sized enterprises: Experiences in the Flemish region of Belgium, Environmental Management and Health, 12 (4), 347-355.

Anand, G., Kodali, R., 2008. Development of a conceptual framework for lean new product development process, International Journal of Product Development, 6 (2), 190-224

Antony, J., 2002. Design for six sigma: A breakthrough business improvement strategy for achieving competitive advantage, Work Study 51 (1)

Baines, T., Lightfoot, H., Williams, G M., Greenough, R., 2006. State-of-the-art in lean design engineering: a literature review on white collar lean, Proceedings of the Institution of Mechanical Engineers Part B-Journal of Engineering Manufacture, 220 (9), 1539-1547

Ballé, F., Ballé, M., 2005. Lean Development, Business Strategy Review, 16 (3), 17-22

Baumann, H., Boons, F., Bragd, A., 2002 Mapping the green product development field: engineering, policy and business perspectives, Journal of Cleaner Production, 10 (5), 409-425.

Baumann, H., Boons, F., Bragd, A., 2002. Mapping the green product development field: engineering, policy and business perspectives. Journal of Cleaner Production 10 (5), 409-425.

Berchicci, L., Bodewes, W., 2005. Bridging environmental issues with new product development, Business Strategy and the Environment, 14 (5), 272-285.

Bevilacqua, M., Ciarapica, F.E., Giacchetta, G. 2007. Development of a sustainable product lifecycle in manufacturing firms: a case study, International Journal of Production Research, 45 (18-19), 4073-4098

Biggs, C., 2009. Exploration of the integration of Lean and environmental improvement, PhD thesis, Cranfield University, UK

Birch, A., Hon, K.K.B., Short, T., 2012. Structure and output mechanisms in Design for Environment (DfE) tools, Journal of Cleaner Production, 35, 50-58.

Boks, C., 2006. The soft side of ecodesign, Journal of Cleaner Production, 14 (15-16), 1346-1356.

Boks, C., McAloone, T.C., 2009. Transitions in sustainable product design research, International Journal of Product Development, 9 (4), 429-449

Boks, C., Stevels, A., 2007. Essential perspectives for design for environment. Experiences from the electronics industry, International Journal of Production Research, 45 (18-19), 4021-4039.

Booth, A., Papaioannou, D., Sutton, A., 2012. Systematic approaches to a successful literature 
review, Sage publications, London

Bovea, M.D., Pérez-Belis, V., 2012. A taxonomy of ecodesign tools for integrating environmental requirements into the product design process, Journal of Cleaner Production, 20 (1), 61-71.

Brezet, J.C., Van Hemel, C., 1997. Ecodesign, A Promising Approach to Sustainable Production and Consumption, UNEP IE, Paris.

Brissaud, D., Zwolinski, P., 2004. End-of-Life-Based Negotiation Throughout the Design Process, CIRP Annals - Manufacturing Technology, 53 (1), 155-158.

Brown, S., Eisenhardt, K., 1995. Product Development: Past Research, Present Findings, and Future. The Academy of Management Review, 20 (2), 343-378

Bryman, A., Bell, E., 2011. Business Research Methods, Oxford University Press.

Chapas, R., Brandt, V., Kulis, L., Crawford, K., 2010. Sustainability in R\&D, Research Technology Management, 53 (6), 60-63.

Chen, C., 2001, Design for the environment: A quality-based model for green product development, Management Science, 47 (2), 250-263

Chen, C.-C., 2010. Application of quality function deployment in the semiconductor industry: A case study, Computers \& Industrial Engineering, 58 (4), 672-679

Choi, J. K., Nies, L. F., Ramani, K., 2008. A framework for the integration of environmental and business aspects toward sustainable product development, Journal of Engineering Design, 19 (5), 431-446.

Chung, Y.-C., Hsu, Y.-W., 2010. Research on the correlation between design for Six Sigma implementation activity levels, new product development strategies and new product development performance in Taiwan's high-tech manufacturers, Total Quality Management and Business Excellence 21 (6), 603-616

Chung, Y-I., Tsai, C.H., 2007. The Effect of Green Design Activities on New Product Strategies and Performance: An Empirical Study among High-tech Companies. International Journal of Management, 24 (2), 276-288.

Clark, K., Fujimoto, T., 1989, Leadtime in automobile product development explaining the Japanese advantage. Journal of Engineering and Technology Management, 6, 25-58.

Cooper, R., Edgett, S., 2008. Maximising productivity in product innovation, Research Technology Management 51 (2), 47-58

Cooper, R., Kleinschmidt, E., 2007. Winning businesses in product development: The critical success factors, Research Technology Management, 50 (3), 52-66

Cooper, R., Slagmulder, R., 2004. Achieving full-cycle cost management, MIT Sloan Management Review, 46 (1), 45-52

De Mendonça, M., Baxter, T.E., 2001. Design for the environment (DFE) - An approach to achieve the ISO 14000 international standardization, Environmental Management and Health, 12 (1), 
del Val Segarra-Oña, M., De-Miguel-Molina, M., Payá-Martínez, A., 2011. A Review Of The Literature On Eco-Design In Manufacturing Industry: Are The Institutions Focusing On The Key Aspects?, The Review of Business Information Systems, 15 (5), 61-67

Donnelly, K., Beckett-Furnell, Z., Traeger, S., Okrasinski, T., Holman, S., 2006. Eco-design implemented through a product-based environmental management system, Journal of Cleaner Production, 14 (15-16), 1357-1367.

Donnelly, K., Salemink, A., Blechinger, F., Schuh, A., Boehm, T., 2004. A Product-Based Environmental Management System, Greener Management International, 46, 57-72.

Dües, C.M., Tan, K.H, Lim, M., 2013. Green as the new lean: How to use lean practices to catalyst the greening of your supply chain, Journal of Cleaner Production, 40, 93-100.

Duflou, J., Dewulf, W., Sas, P., Vanherck, P., 2003. Pro-active Life Cycle Engineering Support Tools, CIRP Annals - Manufacturing Technology, 52 (1), 29-32.

Fiksel, J. (1993) Design for Environment: An Integrated Systems Approach. Proceedings of the IEEE International Symposium on Electronics and the Environment, Arlington, Virginia, 126-131

Fouquet, J-B., 2007. Design for six sigma and lean product development: Differences, similarities and links, The Asian Journal of Quality, 8 (3), 23-34

Gautam, N., Chinnam, R.B., Singh, N., 2007 Design reuse framework: A perspective for lean development, International Journal of Product Development 4 (5)

Gehin, A., Zwolinski, P., Brissaud, D., 2008. A tool to implement sustainable end-of-life strategies in the product development phase, Journal of Cleaner Production, 16 (5), 566-576.

Giannopoulou, E., Yström, Ollila, S., Fredberg, T., Elmquist, M., 2010. Implications of Openness: A Study into (All) the Growing Literature on Open Innovation, Journal of Technology Management \& Innovation, 5 (3), 162-180

Gremyr, I., Fouquet, J-B., 2012. Design for six sigma and lean product development, International Journal of Lean Six Sigma, 3 (1), 45-58

Haque, B., James-Moore, M., 2002. Characteristics of lean product introduction, International Journal of Automotive Technology and Management 2, (3/4), 378-401

Haque, B., James-Moore, M., 2004. Applying lean thinking to new product introduction, Journal of Engineering Design, 15 (1), 1-31

Hasenkamp, T., 2010. Engineering Design for Six Sigma-A Systematic Approach, Quality and Reliability Engineering International, 26, 317-324

Hasenkamp, T., Ölme, A. 2008. Introducing design for six sigma at SKF, International Journal of Six Sigma and Competitive Advantage, 4 (2), 172-189

Hauschild, M.Z., Jeswiet, J., Alting, L., 2004. Design for Environment - Do We Get the Focus Right?, CIRP Annals - Manufacturing Technology, 53 (1), 1-4.

Hines, P., Francis, M., Found, P. 2006. Towards lean product lifecycle management A framework for 
new product development, Journal of Manufacturing Technology Management, 17 (7), 866-887

Hines, P., Holweg, M., Rich, N., 2004. Learning to evolve: A review of contemporary lean thinking, International Journal of Operations \& Production Management 24 (10), 994-1011

Hoffmann, E., 2007. Consumer integration in sustainable product development, Business Strategy and the Environment, 16 (5) , pp. 322-338.

Hoppmann, J., Rebentisch, E., Dombrowski, U., Zahn, T., 2011. A Framework for Organizing Lean Product Development, Engineering Management Journal, 23 (1), 3-15

Huang, Y-C., Wu Y-C., 2010. The effects of organizational factors on green new product success: Evidence from high-tech industries in Taiwan Management Decision, 48 (10), 1539-1567

Ijomah, W.L., McMahon, C.A., Hammond, G.P., Newman, S.T., 2007. Development of design for remanufacturing guidelines to support sustainable manufacturing, Robotics and ComputerIntegrated Manufacturing, 23 (6), 712-719.

Ilgin, M., Gupta, S., 2010. Environmentally conscious manufacturing and product recovery (ECMPRO): A review of the state of the art, Journal of Environmental Management 91, 563-591

Inoue, M., Lindow, K., Stark, R., Tanaka, K., Nahm, Y-E., Ishikawa, H., 2012. Decision-making support for sustainable product creation, Advanced Engineering Informatics, 26 (4), 782-792.

International Organization for Standardization (2011), ISO 14006 Environmental management systems - Guidelines for incorporating ecodesign (Vol. 2011).

Jacobs, L., Herbig, P. 1998, Japanese product development strategies. Journal of Business \& Industrial Marketing, 13, (2), 132-154

Jawahir, I.S., Rouch, K.E., Dillon Jr., O.W., Holloway, L., Hall, A., 2007. Design for sustainability (DFS): New challenges in developing and implementing a curriculum for next generation design and manufacturing engineers, International Journal of Engineering Education, 23 (6), 1053-1064.

Jesson, J., Matheson, L., Kacey, F., 2012. Doing your literature review: Traditional an systematic techniques, Sage Publications.

Johansson, G. 2002. Success Factors for Integration of Ecodesign in Product Development - A Review of State of the Art. Environmental Management and Health, 13 (1), 98-107

Johansson, G., Magnusson, T. 2006. Organising for environmental considerations in complex product development projects: Implications from introducing a "green" sub-project. Journal of Cleaner Production, 14, (15-16), 1368-1376

Johansson, G., 2006. Incorporating environmental concern in product development: A study of project characteristics, Management of Environmental Quality, 17 (4), 421-436.

Johnson, A., 2006. Lessons Learned from six sigma in R\&D, Research Technology Management, 49 (2), 15-19

Jou, Y.T., Chen, C.H., Hwang, C.H., Lin, W.T., Huang, S.J., 2010. A study on the improvements of new product development procedure performance-an application of design for Six Sigma in a semiconductor equipment manufacturer, International Journal of Production Research 48 (19), 
$5573-5591$

Kaebernick, H., Kara, S., Sun, M., 2003. Sustainable product development and manufacturing by considering environmental requirements, Robotics and Computer-Integrated Manufacturing, 19 (6), 461-468.

King, A.A., Lenox, M.J., 2001. Lean and green? An empirical examination of the relationship between lean production and environmental performance, Production and Operations Management 10 (3), 244-256

Kleindorfer, P., Singhal, K., Van Wassenhove L., 2005. Sustainable operations management, Production and Operations Management, 14, (4), 482-492

Lee, K.-H., Kim, J.-W., 2011. Integrating suppliers into green product innovation development: An empirical case study in the semiconductor industry, Business Strategy and the Environment, 20 (8), 527-538.

Lenox, M., King, A., Ehrenfeld, J. 2000. An Assessment of Design-for-Environment Practices in Leading US Electronics Firms, INTERFACES, 30, 83-94

León, H., Farris, J., 2011. Lean Product Development Research: Current State and Future Directions, Engineering Management Journal, 23 (1), 29-51

Letens, G., Farris, J., Van Aken, E., 2011. A Multilevel Framework for Lean Product Development System Design, Engineering Management Journal 23, (1), 69-85

Liker, J., Morgan, J., 2006. The Toyota Way in Services: The Case of Lean Product Development, Academy of Management Perspectives, 20 (2), 5-20

Liker, J., Morgan, J., 2011. Lean Product Development as a System: A Case Study of Body and Stamping Development at Ford, Engineering Management Journal 23, (1), 16-28

Lindahl, M., 2006. Engineering designers' experience of design for environment methods and tools Requirement definitions from an interview study, Journal of Cleaner Production, 14 (5), 487496.

Lindlöf, L., Söderberg, B., 2011. Lean product development provides manufacturing value, International Journal of Technology Intelligence and Planning 7 (3), 269-279

Ljungberg, L.Y., 2007. Materials selection and design for development of sustainable products, Materials \& Design, 28 (2), 466-479.

Luttropp, C., Lagerstedt, J., 2006. EcoDesign and The Ten Golden Rules: generic advice for merging environmental aspects into product development, Journal of Cleaner Production, 14 (15-16), 1396-1408.

Mascle, C., Zhao, H.P., 2008. Integrating environmental consciousness in product/process development based on life-cycle thinking, International Journal of Production Economics, 112 (1), 5-17.

Mathieux, F., Froelich, D., Moszkowicz, P., 2008. ReSICLED: a new recovery-conscious conceptual for complex products based on a multicriteria assessment of the recoverability, Journal of Cleaner 
Production, $16(3), 277-298$.

Maxwell, D., Sheate, W., van der Vorst, R., 2006. Functional and systems aspects of the sustainable product and service development approach for industry, Journal of Cleaner Production, 14 (17), 1466-1479.

Maxwell, D., van der Vorst, R., 2003. Developing sustainable products and services, Journal of Cleaner Production, 11 (8), 883-895.

Monden, Y., 1983. The Toyota Production System, Productivity Press, Portland, OR.

Müller, M., 2012. Design-driven innovation for sustainability: A new method for developing a sustainable value proposition, International Journal of Innovation Science, 4 (1), 11-23.

Nambisan, S., Wilemon, D., 2000. Software Development and New Product Development: Potentials for Cross-Domain Knowledge Sharing. IEEE Transactions on Engineering Management, 47 (2), 211-220

Nepal, B., Yadav, Yadav, O., Solanki, R., 2011. Improving the NPD Process by Applying Lean Principles: A Case Study, Engineering Management Journal 23, (1), 65-81

$\mathrm{Ni}$, Y., Fan, F., Zheng, Y., Zhang, Y., 2011. Value engineering-driven lean product development, Advanced Science Letters 4 (6-7), 2440-2445

Ohno, T., 1988. The Toyota Production System: Beyond Large-Scale Production, Productivity Press, Portland, OR.

Ölundh Sandström, G., Tingström, J., 2008. Management of radical innovation and environmental challenges: Development of the DryQ capacitor at ABB, European Journal of Innovation Management, 11 (2), 182-198

Park, J-H., Seo K-K., 2006. A knowledge-based approximate life cycle assessment system for evaluating environmental impacts of product design alternatives in a collaborative design environment, Advanced Engineering Informatics, 20 (2), 147-154

Pialot, O., Millet D., Tchertchian, N., 2012. How to explore scenarios of multiple upgrade cycles for sustainable product innovation: the "Upgrade Cycle Explorer" tool, Journal of Cleaner Production, 22, 19-31

Pialot, O., Millet, D., Tchertchian, N., 2012. How to explore scenarios of multiple upgrade cycles for sustainable product innovation: The "upgrade Cycle Explorer" tool, Journal of Cleaner Production, 22 (1), 19-31.

Pigosso, D.C.A., Zanette, E.T., Filho, A.G., Ometto, A.R., Rozenfeld, H., 2010. Ecoconceptuals focused on remanufacturing, Journal of Cleaner Production, 18 (1), 21-31.

Porter, M., van der Linde, C. (1995) Green and Competitive, Harvard Business Review: SeptemberOctober, 120-134

Poudelet, V., Chayer, J.-A., Margni, M., Pellerin, R., Samson, R., 2012. A process-based approach to operationalize life cycle assessment through the development of an eco-design decisionsupport system, Journal of Cleaner Production, 33, 192-201. 
Ramani, K., Ramanujan, D., Bernstein, W. Zhao, F., Sutherland, J., Handwerker, C., Choi, J.-K., Kim, H., Thurston, D., 2010. Integrated sustainable life cycle design: A review, Journal of Mechanical Design, 132, 1-15

Sakao, T., 2009. Quality engineering for early stage of environmentally conscious design, TQM Journal 21 (2), 182-193

Santini, A., Herrmann, C., Passarini, F., Vassura, I., Luger, T., Morselli, L., 2010. Assessment of Ecodesign potential in reaching new recycling targets, Resources, Conservation and Recycling, 54 (12), 1128-1134.

Santos-Reyes and Lawlor-Wright, 2001, A design for the environment methodology to support an environmental management system, Integrated Manufacturing Systems, 12 (5), 323-332

Saranga, H., 2011. Optimal deployment of parallel teams in new product development, International Journal of Operational Research 10 (2), 137-159

Schulze, A., Störmer, T., 2012. Lean product development - enabling management factors for waste elimination, International Journal of Technology Management, 57 (1/2/3), 71-91

Seuring, S, Müller, M., 2008. From a Literature review to a conceptual framework for sustainable supply chain management, Journal of Cleaner Production, 6, 1899-1710

Shirwaiker, R., Okudan G., 2011. Contributions of TRIZ and axiomatic design to leanness in design: an investigation, Procedia Engineering, 9, 730-735

Short, T., Lee-Mortimer, A., Luttropp, C., Johansson, G., 2012. Manufacturing, sustainability, ecodesign and risk: Lessons learned from a study of Swedish and English companies. Journal of Cleaner Production, 37, 342-352

Short, T., Lee-Mortimer, A., Luttropp, C., Johansson, G., 2012. Manufacturing, sustainability, ecodesign and risk: Lessons learned from a study of Swedish and English companies, Journal of Cleaner Production, 37, 342-352.

Simon, M., Evans, S., McAloone, T.C., Sweatman, A., Bhamra, T. and Poole, S., 1998. Ecodesign Navigator, Manchester Metropolitan University, Cranfield University \& EPSRC, UK

Simon, M., Poole, S., Sweatman, A., Evans, S., Bhamra, T., 2000. Environmental priorities in strategic product development, Business Strategy and the Environment, 9 (6), 367-377

Smith, S., Yen, C-C., 2010. Green product design through product modularization using atomic theory, Robotics and Computer-Integrated Manufacturing, 26 (6), 790-798.

Song, J-S., Lee, K-M., 2010. Development of a low-carbon product design system based on embedded GHG emissions, Resources, Conservation and Recycling, Volume 54, Issue 9, July 2010, Pages 547-556.

Soylu, K., Dumville, J.C., 2011. Design for environment: The greening of product and supply chain, Maritime Economics \& Logistics, 13 (1), 29-43.

Strauss, A., Corbin, J., 1990. Basics of Qualitative Research: Grounded Theory Procedures and 
Techniques, Sage Publications

Summers, G., Scherpereel, C., 2008. Decision making in product development: are you outside-in or inside-out?, Management Decision 46 (9), 1299-1312.

Sun, H., Zhao, Y., Yau, H-K., 2009. The relationship between quality management and the speed of new product development, TQM Journal 21 (6), 576-588

Sundin, E., Bras, B., 2005. Making functional sales environmentally and economically beneficial through product remanufacturing, Journal of Cleaner Production, 13 (9), 913-925.

Sundin, E., Elo, K., Lee, H.M., 2012. Design for automatic end-of-life processes, Assembly Automation, 32 (4), 389-398

Thomas, M., Singh, N., 2006. Complexity reduction in product design and development using Design for Six Sigma, International Journal of Product Development, 3 (3-4), 319-336

Tseng, H-E., Chang, C-C., Li, J-D., 2008. Modular design to support green life-cycle engineering, Expert Systems with Applications, 34 (4), 2524-2537.

Vercalsteren, A., 2001. Integrating the ecodesign concept in small and medium-sized enterprises: Experiences in the Flemish region of Belgium, Environmental Management and Health 12, (4), 347-355

Vinodh, S., 2011. Environmental conscious product design using CAD and CAE, Clean Technologies and Environmental Policy, 13 (2), 359-367

Vinodh, S., Rathod, G., 2010. Integration of ECQFD and LCA for sustainable product design, Journal of Cleaner Production, 18 (8), 833-842

Vinodh, S., Rathod, G., 2011. Application of ECQFD for enabling environmentally conscious design and sustainable development in an electric vehicle, Clean Technologies and Environmental Policy, 13 (2), 381-396

Wang, L., Ming, X.G., Kong, F.B., Li, D., Wang, P.P., 2011. Focus on implementation: A framework for lean product development, Journal of Manufacturing Technology Management 23 (1), 4-24

WCED, 1987. Our Common Future. Oxford University Press, London

Welo, T., 2011. On the application of lean principles in Product Development: A commentary on models and practices, International Journal of Product Development, 13 (4), 316-342

Womack, J., Jones D., Roos ,D., 1991. The Machine That Changed the World: The Story of Lean Production, HarperPerennial

Womack, J., Jones, D., 1996. Lean Thinking: Banish Waste and Create Wealth in Your Corporation, Simon and Schuster.

Yang, C.,J., Chen, J.L., 2011. Accelerating preliminary eco-innovation design for products that integrates case-based reasoning and TRIZ method, Journal of Cleaner Production 19 (9-10), 998-1006

Yang, K., Cai, X., 2009 The integration of DFSS, lean product development and lean knowledge 
management, International Journal of Six Sigma and Competitive Advantage 5 (1), 75-99

Zhang, L., Zhan, Y., Liu, Z.F., Zhang, H.C., Li, B.B., 2011. Development and analysis of design for environment oriented design parameters, Journal of Cleaner Production, 19 (15), 1723-1733. 